ArgOn national laboratory

\title{
Heat Exchanger Temperature Response for Duty-Cycle Transients in the NGNP/HTE
}

Nuclear Engineering Division 


\begin{abstract}
About Argonne National Laboratory
Argonne is a U.S. Department of Energy laboratory managed by UChicago Argonne, LLC under contract DE-AC02-06CH11357. The Laboratory's main facility is outside Chicago, at 9700 South Cass Avenue, Argonne, Illinois 60439. For information about Argonne, see www.anl.gov.
\end{abstract}

\title{
Availability of This Report
}

This report is available, at no cost, at http://www.osti.gov/bridge. It is also available on paper to the U.S. Department of Energy and its contractors, for a processing fee, from:

U.S. Department of Energy

Office of Scientific and Technical Information

P.O. Box 62

Oak Ridge, TN 37831-0062

phone (865) 576-8401

fax (865) 576-5728

reports@adonis.osti.gov

\begin{abstract}
Disclaimer
This report was prepared as an account of work sponsored by an agency of the United States Government. Neither the United States Government nor any agency thereof, nor UChicago Argonne, LLC, nor any of their employees or officers, makes any warranty, express or implied, or assumes any legal liability or responsibility for the accuracy, completeness, or usefulness of any information, apparatus, product, or process disclosed, or represents that its use would not infringe privately owned rights. Reference herein to any specific commercial product, process, or service by trade name, trademark, manufacturer, or otherwise, does not necessarily constitute or imply its endorsement, recommendation, or favoring by the United States Government or any agency thereof. The views and opinions of document authors expressed herein do not necessarily state or reflect those of the United States Government or any agency thereof, Argonne National Laboratory, or UChicago Argonne, LLC.
\end{abstract}




\section{Heat Exchanger Temperature Response for Duty-CycleTransients in the NGNP/HTE}

by

R.B. Vilim

Nuclear Engineering Division, Argonne National Laboratory

September 2008

work sponsored by

U. S. Department of Energy,

Office of Nuclear Energy, Science and Technology

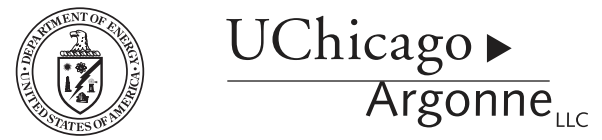




\section{TABLE OF CONTENTS}

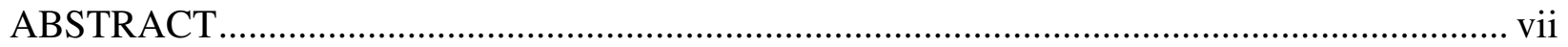

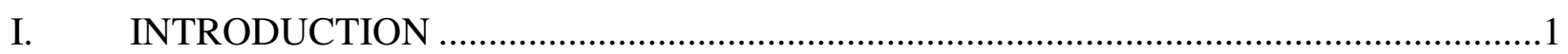

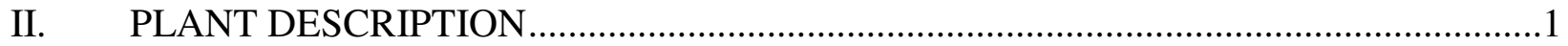

III DUTY-CYCLE TRANSIENTS.....................................................................

A. Change in Electric Generator Load ..........................................................

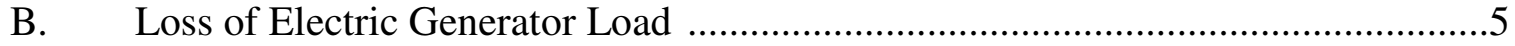

IV. PLANT CONTROL SYSTEM ......................................................................

A. Integrated Plant Load Schedule ..........................................................

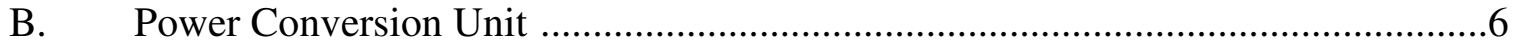

B.1 Inventory Control ......................................................................... 7

B.2 Turbine Bypass Control ................................................................ 7

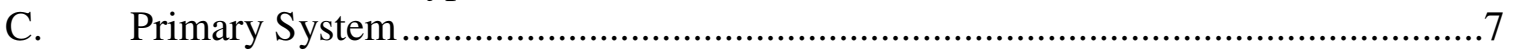

D. High Temperature Steam Electrolysis Plant ..................................................

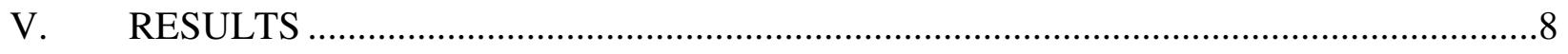

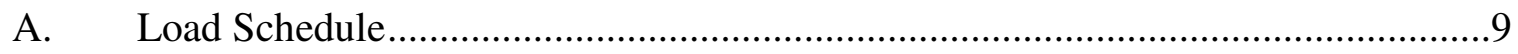

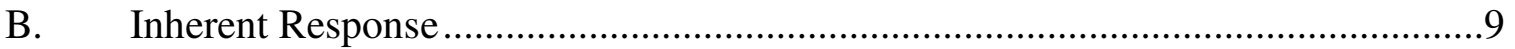

C. Change in Electric Generator Load................................................................18

C.1 Ramp of Three Percent per Minute........................................................19

C.2 Step of Ten Percent .....................................................................22

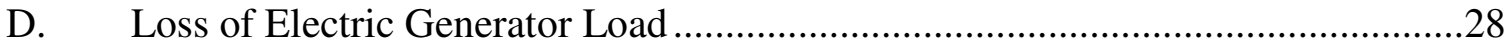

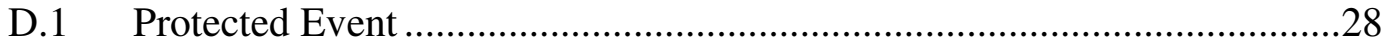

D.2 Unprotected Event .................................................................... 33

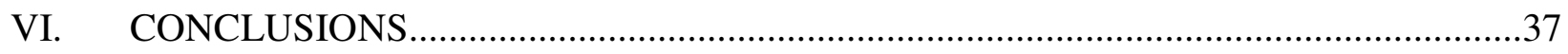

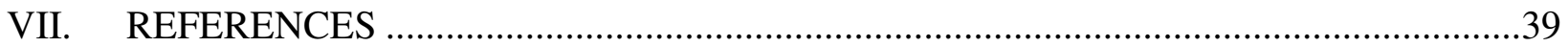




\section{LIST OF FIGURES}

$1 \quad$ Overall Equipment Configuration for NGNP-HTE Plant .......................................2

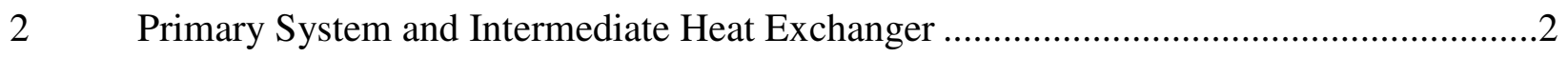

3 Power Conversion Unit Equipment Configuration ...............................................

$4 \quad$ High Temperature Steam Electrolysis Equipment Configuration ................................4

$5 \quad$ Load Schedule for Reference Interface - HTE Temperatures.................................... 10

$6 \quad$ Load Schedule for Reference Interface - Hot Side Helium Temperatures ......................10

$7 \quad$ Load Schedule for Reference Interface - Cold Side Helium Temperatures ....................10

$8 \quad$ Load Schedule for Reference Interface - Helium Pressures ..................................... 10

$9 \quad$ Load Schedule for Reference Interface - Component Powers ................................... 10

10 Plant Configuration for Assessment of Combined-Plant Stability ...............................15

11 Loop Reactor Response to Intermediate System Temperature Perturbation - Forcing

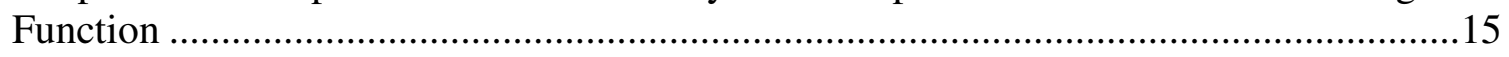

12 Loop Reactor Response to Intermediate System Temperature Perturbation - Core Temperatures. Mixing Time Constant of $20 \mathrm{~s}$...................................................... 15

13 Loop Reactor Response to Intermediate System Temperature Perturbation - Reactivity Components. Mixing Time Constant of $20 \mathrm{~s}$............................................................16

14 Loop Reactor Response to Intermediate System Temperature Perturbation - Fuel Thermal Power. Mixing Time Constant of $20 \mathrm{~s}$.....................................................16

15 Loop Reactor Response to Intermediate System Temperature Perturbation - Outlet Temperature. Mixing Time Constant of $20 \mathrm{~s}$

16 Loop Reactor Response to Intermediate System Temperature Perturbation - Reactor Temperature Change. Mixing Time Constant of 20 s................................................16

17 Change in Core Inlet and Outlet Temperatures as a Function of Mixing Time Constant 17

18 Power in Fuel as a Function of Mixing Time Constant .........................................17 
19 Ramp of Generator Load of Three Percent per Minute - Forcing Functions Long Term

20 Ramp of Generator Load of Three Percent per Minute - Normalized Inventory - Long Term

21 Ramp of Generator Load of Three Percent per Minute - Flowrates - Long Term .21

22 Ramp of Generator Load of Three Percent per Minute - Shaft Speeds - Long Term .....21

23 Ramp of Generator Load of Three Percent per Minute - Turbomachine Powers - Long Term

24 Ramp of Generator Load of Three Percent per Minute - IHX Temperatures Long Term.

25 Reference Interface Power Conversion Unit with Bypass

26 Step of Generator Load of Ten Percent - Forcing Functions - Short Term. .25

27 Step of Generator Load of Ten Percent - Forcing Functions - Long Term .25

28 Step of Generator Load of Ten Percent - Normalized Inventory - Short Term.............25

29 Step of Generator Load of Ten Percent - Normalized Inventory - Long Term ..............25

30 Step of Generator Load of Ten Percent - Flowrates - Short Term ..............................26

31 Step of Generator Load of Ten Percent - Flowrates - Long Term..............................26

32 Step of Generator Load of Ten Percent - Shaft Speeds - Short Term .........................26

33 Step of Generator Load of Ten Percent - Shaft Speeds - Long Term...........................26

34 Step of Generator Load of Ten Percent - Turbomachine Powers - Short Term .............27

35 Step of Generator Load of Ten Percent - Turbomachine Powers - Long Term .............27

36 Step of Generator Load of Ten Percent - IHX Temperatures - Short Term ..................27

37 Step of Generator Load of Ten Percent - IHX Temperatures - Long Term .................27

38 Protected Loss of Generator Load - Forcing Functions - Short Term .........................30

39 Protected Loss of Generator Load - Forcing Functions - Long Term ..........................30 
40 Protected Loss of Generator Load - Normalized Inventory - Short Term......................30

41 Protected Loss of Generator Load - Normalized Inventory - Long Term ......................30

42 Protected Loss of Generator Load - Mass Flowrates - Short Term ...............................31

43 Protected Loss of Generator Load - Mass Flowrates - Long Term .............................31

44 Protected Loss of Generator Load - Shaft Speeds - Short Term .................................31

45 Protected Loss of Generator Load - Shaft Speeds - Long Term................................31

46 Protected Loss of Generator Load - TurboMachine Powers - Short Term.....................32

47 Protected Loss of Generator Load - TurboMachine Powers - Long Term .....................32

48 Protected Loss of Generator Load - IHX Temperatures - Short Term ........................32

49 Protected Loss of Generator Load - IHX Temperatures - Long Term .........................32

$50 \quad$ Unprotected Loss of Generator Load - Forcing Functions - Short Term ......................34

$51 \quad$ Unprotected Loss of Generator Load - Forcing Functions - Long Term .....................34

52 Unprotected Loss of Generator Load - Normalized Inventory - Short Term .................34

53 Unprotected Loss of Generator Load - Normalized Inventory - Long Term .................34

$54 \quad$ Unprotected Loss of Generator Load - Mass Flowrates - Short Term ........................35

$55 \quad$ Unprotected Loss of Generator Load - Mass Flowrates - Long Term .........................35

56 Unprotected Loss of Generator Load - Shaft Speeds - Short Term.............................35

57 Unprotected Loss of Generator Load - Shaft Speeds - Long Term ............................35

58 Unprotected Loss of Generator Load - Turbomachine Powers - Short Term ................36

59 Unprotected Loss of Generator Load - Turbomachine Powers - Long Term.................36

$60 \quad$ Unprotected Loss of Generator Load - IHX Temperatures - Short Term .....................36

61 Unprotected Loss of Generator Load - IHX Temperatures - Long Term.....................36 


\section{LIST OF TABLES}

I Conditions in NGNP/HTE Plant with Reference Interface

II Values of Design Parameters for Annular Unit-Cell Representation of Fuel Element ....13

III Upper Bound for Differential Worth of Operating Control Rods for GT-MHR .............13

IV Deviation of Control Rod Reactivity Coefficients for VHTR .....................................14

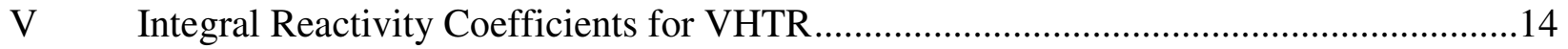

VI Operating Mode and Associated Control Systems ................................................20

VII Description of Control System A Individual Controllers ...........................................20

VIII Description of Control System B Individual Controllers...........................................20

IX Description of Control System C Individual Controllers........................................23

$\mathrm{X} \quad$ Description of Control System D Individual Controllers ...........................................23 


\title{
HEAT EXCHANGER TEMPERATURE RESPONSE FOR DUTY-CYCLE TRANSIENTS IN THE NGNP/HTE
}

\author{
R.B. Vilim
}

\begin{abstract}
Control system studies were performed for the Next Generation Nuclear Plant (NGNP) interfaced to the High Temperature Electrolysis (HTE) plant. Temperature change and associated thermal stresses are important factors in determining plant lifetime. In the NGNP the design objective of a 40 year lifetime for the Intermediate Heat Exchanger (IHX) in particular is seen as a challenge. A control system was designed to minimize temperature changes in the IHX and more generally at all high-temperature locations in the plant for duty-cycle transients. In the NGNP this includes structures at the reactor outlet and at the inlet to the turbine.
\end{abstract}

This problem was approached by identifying those high-level factors that determine temperature rates of change. First are the set of duty cycle transients over which the control engineer has little control but which none-the-less must be addressed. Second is the partitioning of the temperature response into a quasi-static component and a transient component. These two components are largely independent of each other and when addressed as such greater understanding of temperature change mechanisms and how to deal with them is achieved. Third is the manner in which energy and mass flow rates are managed. Generally one aims for a temperature distribution that minimizes spatial non-uniformity of thermal expansion in a component with time. This is can be achieved by maintaining a fixed spatial temperature distribution in a component during transients. A general rule of thumb for heat exchangers is to maintain flow rate proportional to thermal power. Additionally the product of instantaneous flow rate and heat capacity should be maintained the same on both sides of the heat exchanger. Fourth inherent mechanisms for stable behavior should not be compromised by active controllers that can introduce new feedback paths and potentially create under-damped response.

Applications of these principles to the development of a plant control strategy for the reference NGNP/HTE plant can be found in the body of this report. The outcome is an integrated plant/control system design. The following conclusions are drawn from the analysis.

- The plant load schedule can be managed to maintain near-constant hot side temperatures over the load range in both the nuclear and chemical plant. 
- The reactor open-loop response is inherently stable resulting mainly from a large Doppler temperature coefficient compared to the other reactivity temperature feedbacks.

- The typical controller used to manage reactor power production to maintain reactor outlet temperature at a setpoint introduces a feedback path that tends to destabilize reactor power production in the NGNP.

- A primary loop flow controller that forces primary flow to track PCU flow rate is effective in minimizing spatial temperature differentials within the IHX.

- Inventory control in both the primary and PCU system during ramp load change transients is an effective means of maintaining high NGNP thermal efficiency while at reduced electric load.

- Turbine bypass control is an effective means for responding to step changes in generator load when equipment capacity limitations prevent inventory control from being effective.

- Turbine bypass control is effective in limiting PCU shaft over speed for the loss of generator load upset event.

- The proposed control strategy is effective in limiting time variation of the differential spatial temperature distribution in the IHX during transients. Essentially the IHX can be made to behave in a manner where each point in the IHX experiences approximately the same temperature rate of change during a transient.

- The stability of the closed-loop Brayton cycle was found to be sensitive to where one operates on the turbo-machine performance maps. There are competing interests: more stable operation means operating on the curves at points that reduce overall cycle efficiency.

Future work should address in greater detail elements that came to light in the course of this work. Specifically:

- A stability analysis should be performed to identify the phenomena that control reactor outlet temperature stability when operating with the Reactor Outlet Temperature Controller. The goal is to identify a better performing controller.

- Future simulations should be performed with multiple axial nodes. The single axial node model for the core used in this work gives rise to an initial core reactor outlet temperature perturbation that is a numerical artifact. 
$\circ$ The tradeoffs referred to above regarding the dependence of Brayton cycle stability and efficiency on performance curve characteristics and use need to be better understood.

- The role of xenon was neglected in this work and needs to be included in future work. 


\section{INTRODUCTION}

Market studies suggest that several industries in the U.S. could benefit from a stable, secure, and inexpensive source of hydrogen and process heat. These industries include producers of fertilizers and refiners of carbon-rich crude oil. In the scenario envisioned nuclear hydrogen would replace hydrogen currently obtained from steam-methane reforming of natural gas. Industries that have in the past met their hydrogen needs with natural gas are faced with growing environmental constraints and increased global competition for this commodity. Production of hydrogen within the U.S. using nuclear power could reduce the economic uncertainty these industries now face.

The production of hydrogen using nuclear power is being examined across a wide range of economic and technical areas. These include process technologies, material needs and capabilities, supply and distribution system requirements, and integration of the nuclear and chemical plants, the subject of this report.

The goal of this work is to develop requirements for the control and protection systems that will be needed to operate the NGNP as a co-producer of hydrogen and process heat. The plant must operate economically, on demand, and safely. The investigation of control and protection system requirements is addressed through plant transient analyses. A dynamic systems simulation code is used to predict plant response to several events drawn from the plant duty-cycle list. These include transients associated with normal operating maneuvers during load change and with anticipated upsets including loss of load. The key issue is whether operational and safety goals can be achieved while simultaneously designing for a 40 year lifetime. This work generates time dependent temperature profiles for components that can be of used by equipment designers to determine thermal stresses and from this component lifetime. The focus is on the Intermediate Heat Exchanger (IHX) since this component is believed to be the most limiting with respect to plant lifetime.

\section{PLANT DESCRIPTION}

This report is the third in a series in FY08 [1, 2] examining the NGNP/HTE plant operating with the Reference Interface. A description of the Reference Interface including detailed information for individual component sizes appeared earlier in [3]. The Reference Interface originally appeared as Case 6 of [4].

The Reference Interface is shown in overview in Figure 1. In this figure the combined plant appears as three modules: the Primary System, the Power Conversion System, and the High Temperature Electrolysis plant. The lines connecting these three modules represent the interface. Each of these three modules is shown in greater detail in Figures 2 through 4. 


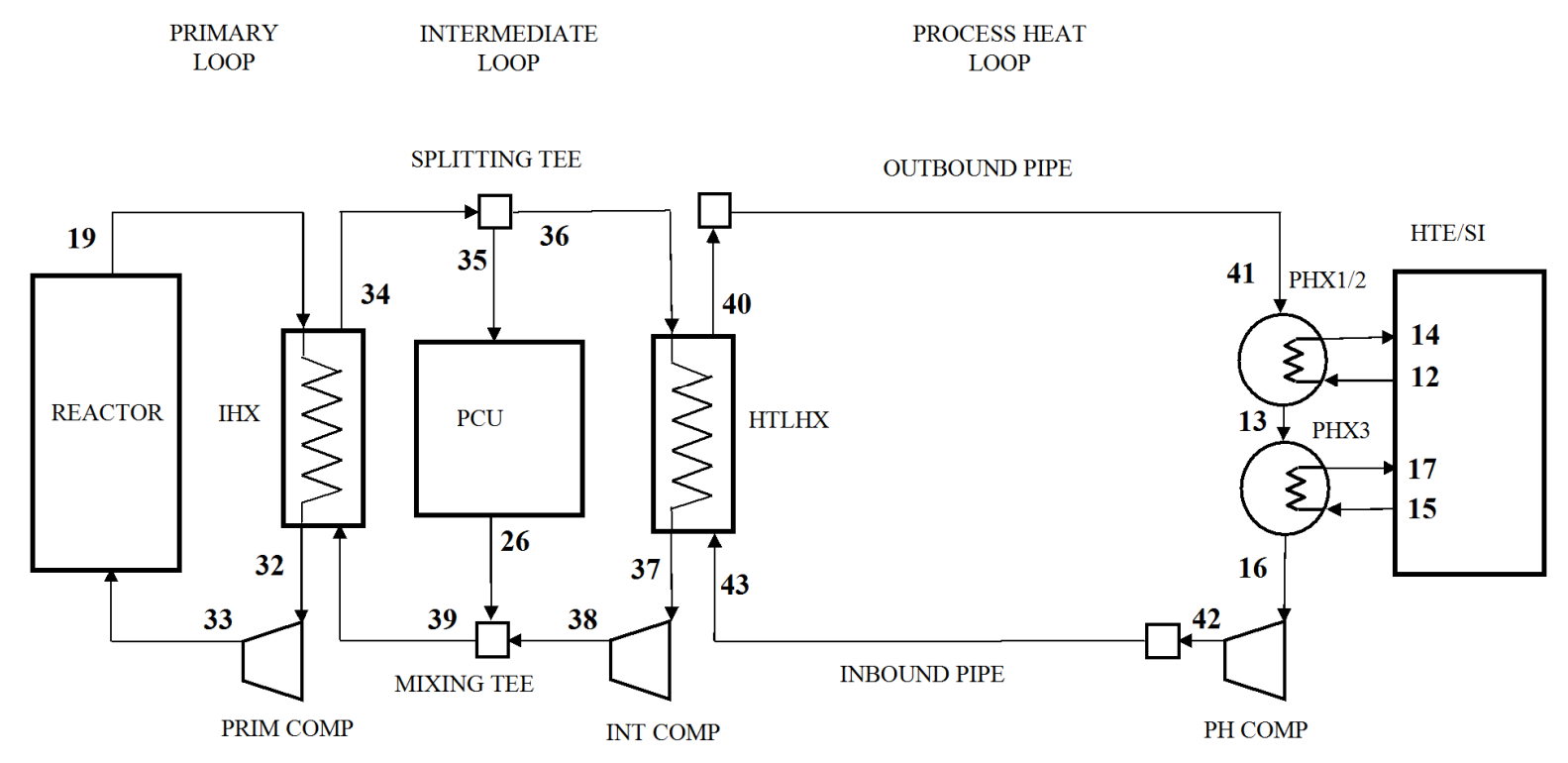

Figure 1 Overall Equipment Configuration for NGNP-HTE Plant

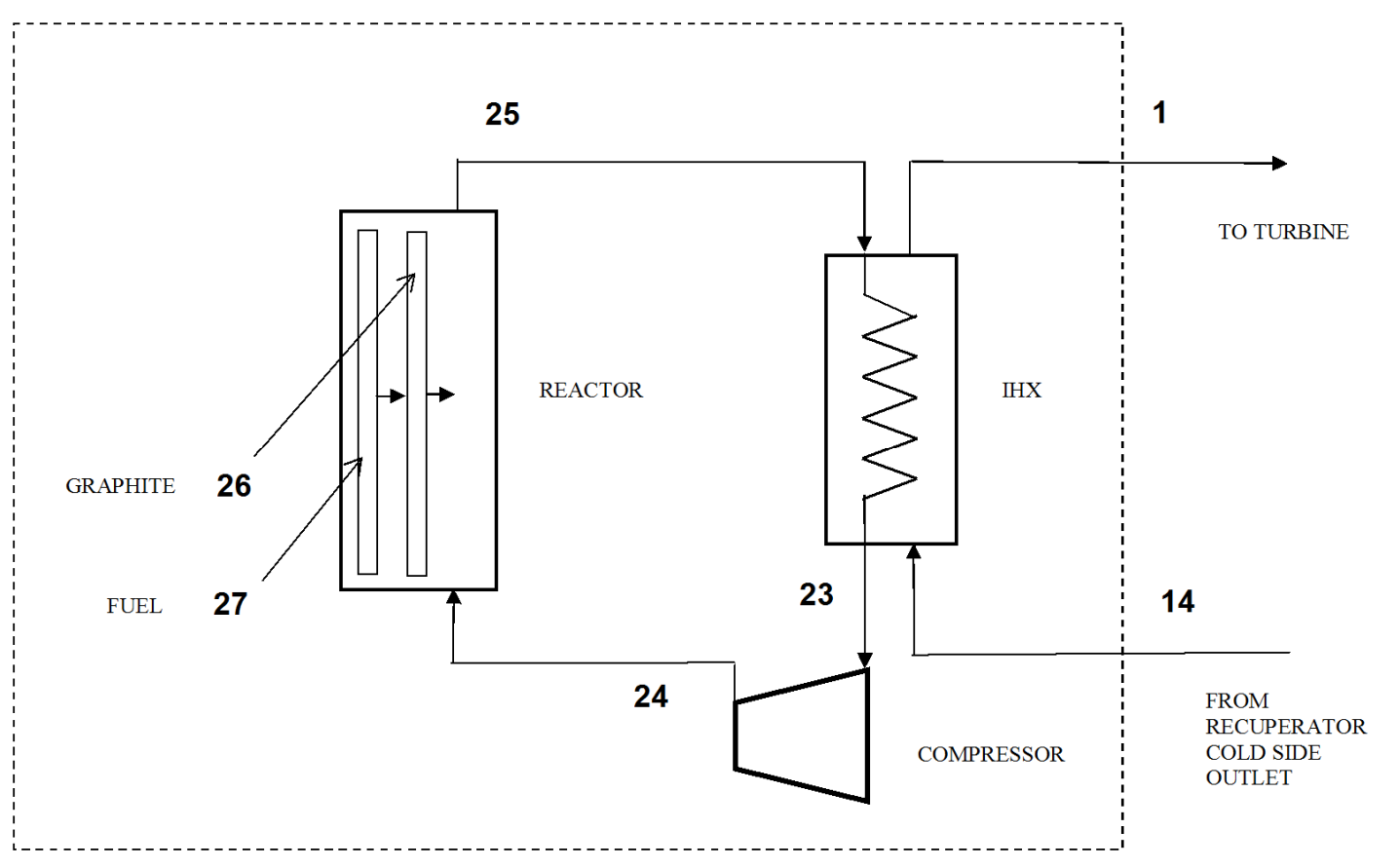

Figure 2 Primary System and Intermediate Heat Exchanger 


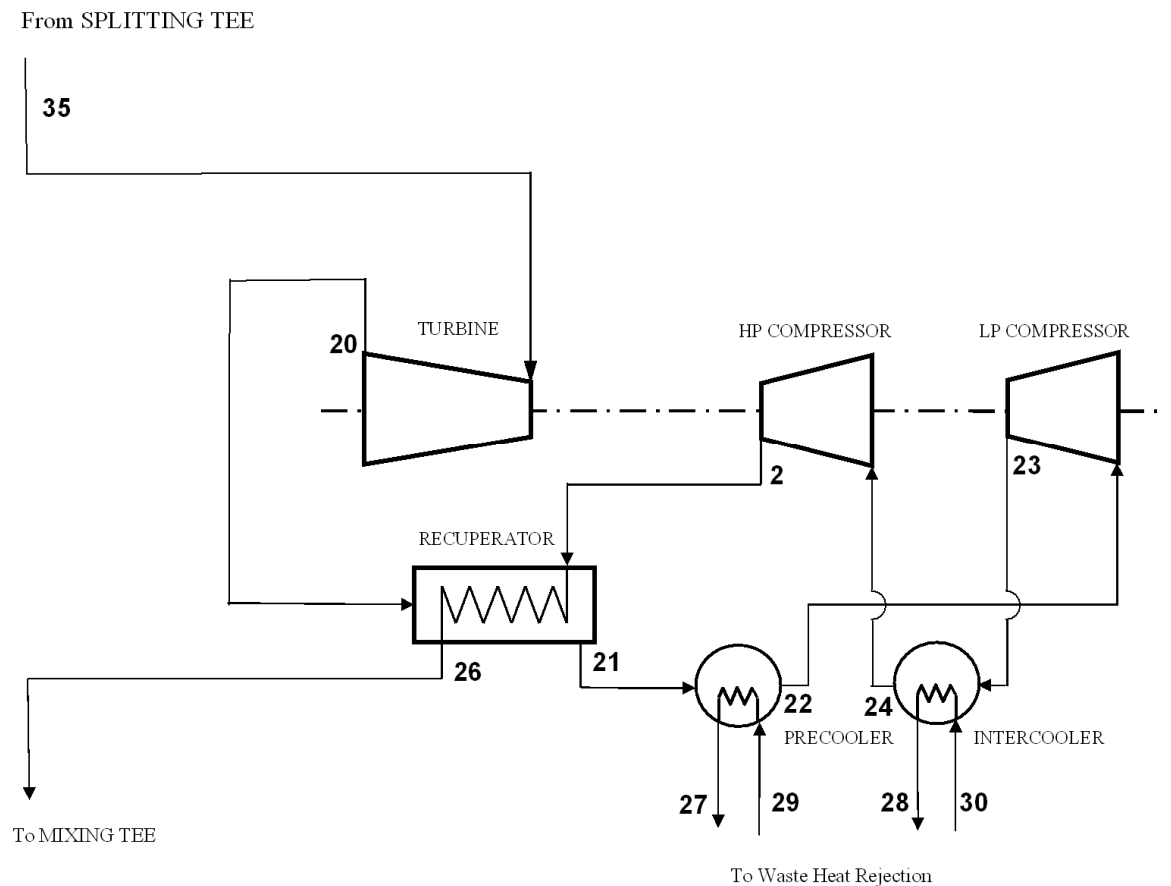

Figure 3 Power Conversion Unit Equipment Configuration

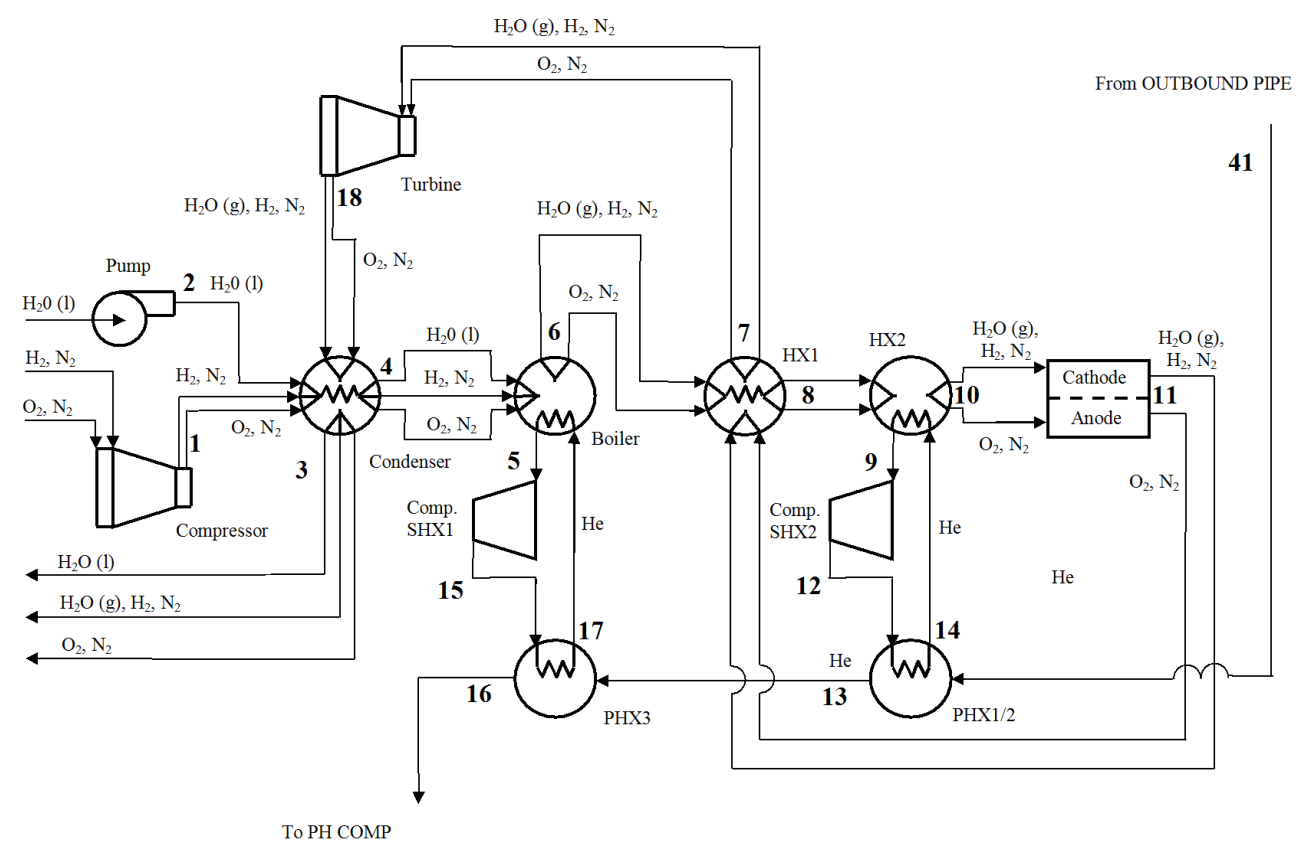

Figure 4 High Temperature Steam Electrolysis Equipment Configuration 
The performance of the Reference Interface is described in [5]. In that work the full power condition, the combined plant efficiency, and the partial power load schedule were calculated. The electrolytic cell is operated exothermically compared to a more recent trend where it is operated thermal neutral.[6] In [6], an ASR of $0.4 \mathrm{ohms}-\mathrm{cm}^{2}$, current density of $0.25 \mathrm{amp} / \mathrm{cm}^{2}$, and cell outlet temperature of $850 \mathrm{C}$ compare with values of $0.7 \mathrm{ohms}-\mathrm{cm}^{2}, 0.45 \mathrm{amps} / \mathrm{cm}^{2}$, and $970 \mathrm{C}$, respectively, used in the present work. The values of the main operating parameters in the Reference Interface plant are summarized in Table I.

Table I Conditions in NGNP/HTE Plant with Reference Interface

\begin{tabular}{|l|l|}
\hline Reactor & \\
\hline Power, MW & 600 \\
\hline Outlet Temperature, C & 887 \\
\hline Inlet Temperature, C & 490 \\
\hline PCU & \\
\hline Turbine Inlet Temperature, C & 870 \\
\hline HP Compressor Outlet Pressure, C & 7.4 \\
\hline LP Compressor Outlet Pressure, C & 4.1 \\
\hline HTE & \\
\hline Cell Outlet Temperature, C & 970 \\
\hline Cell Pressure, MPa & 5.0 \\
\hline
\end{tabular}

\section{DUTY-CYCLE TRANSIENTS}

The economics of a nuclear plant are typically optimized for a plant lifetime of 40 years. The optimization takes into account accumulation of material damage in components from thermal stress, radiation, and mechanical loading. In this work we focus on thermal stress. Data for temperature gradients in NGNP components during operational transients are calculated and provided for use to equipment designers. At this time the IHX appears to be the component with the limiting lifetime because of its elevated temperature and the presence of duty-cycle transients. These transients cause a temporary imbalance between energy production in the nuclear plant and energy absorption in the chemical plant. These imbalances lie across the IHX and so with them come time-varying temperatures. Time-varying mechanical loading stresses are also a concern. These are experienced when the pressure differential across a component increases beyond that at normal operation. Both the IHX and recuperator can experience operational and upset induced time-varying thermal and mechanical-loading stresses.

A duty cycle list provides the type and frequency of plant transients. By calculating the temperature time-history for these events one can then obtain the corresponding time-varying thermally-induced stresses. From this the damage a component will sustain over a 40 year lifetime can be estimated.

The plant control system is an important element in limiting damage from transients. The control system can act to reduce temperature changes during plant transients and so reduce 
thermal stresses. The design of the control system to limit thermal stresses during duty-cycle transients is then an important factor in limiting accumulated damage.

An important consideration in the design of the combined NGNP/HTE plant is the nature of the transients in the duty cycle list. If there are transients unique to the coupled nature of the plant, then these need to be identified. An important concern is the transients induced in the nuclear plant by coupled-plant behavior. These have greater safety and maintenance consequences than those induced in the chemical plant. Identification of unique duty-cycle events in the combined plant that impact the nuclear plant is straightforward since the nuclear plant interfaces with the chemical plant primarily though electricity produced at the generator. More than 90 percent of the useful reactor thermal power (i.e. that reactor power not ultimately rejected as waste heat) ends up being communicated to the chemical plant as electrical power passed through the NGNP/HTE interface. Thus transients in the chemical plant act on the reactor through changed electric power load and are therefore from the standpoint of the nuclear plant classic electric-load transients. And transients in the nuclear plant are just the classic transients for an electricity-only nuclear plant.

Therefore the duty-cycle events for the NGNP/HTE that cause thermal fatigue in the nuclear plant will be essentially the same set of transients considered in electricity-only nuclear plants. These transients are described below.

\section{A. Change in Electric Generator Load}

The plant must meet a demand for a ten-percent step change in hydrogen production rate at the plant fence. This must be achieved without exceeding operating limits. The operating limits detail among other things maximum temperature rates of change in components. The limits are a function of material properties, component design, and required component lifetime. The determination of limits is outside the scope of the current project. We calculate plant temperature response for the ten percent load change transient. These results can then be compared against operating limits when they become available.

The plant must similarily meet a demand for a three percent per minute change in hydrogen production rate at the plant fence.

\section{B. Loss of Electric Generator Load}

If the generator load is lost, as in the case where the hydrogen production plant goes off line, then an imbalance between nuclear heat source and sink is created. With no means of dissipating the heat formerly associated with electricity production, the reactor will scram on operator or protection system action. Core power will be reduced to decay heat levels. The PCU turbomachine shaft will over speed as a result of lost mechanical load. Short term goals in this upset are to prevent rapid temperature change in the IHX and limit PCU shaft over speed. A long term goal is to cool down the hot side of the primary system at a slow rate. 
Also of interest is the loss of load upset where the reactor fails to scram. This event is a Beyond Design Basis event and an Anticipated Transient without Scram (ATWS) event. The Nuclear Regulatory Commission has in recent years required safety analysis of ATWS events.

\section{CONTROL SYSTEM}

The plant control system functions to limit temperature rates of change during plant load change and upset events. This is achieved at two different levels. In the time asymptote following a plant perturbation the control system through control variable setpoints (with values assigned as a function of steady-state power) takes the plant to a new steady-state condition. The setpoint values are chosen so that hot side temperatures remain little changed. In the shorter term the control system manages the dynamic response of the plant so that the transition between steady states is stable and with minimal overshoot of process variables.

\section{A. Integrated Plant Load Schedule}

The load schedule specifies for normal at-power operation a unique plant steady state at each power level over the normal operating range, typically from 25 to 100 percent of full power. This includes the values of all plant forcing functions such as turbo-machine power inputs and reactor and cooler heat rates.

In plant transient analyses, the load schedule defines conditions at which a transient begins and in some cases ends. If the transient is one that occurs during normal operation, then the start and end states are found on the load schedule. If the transient is an upset event, then while it begins from a point on the load schedule it may terminate at some stable off-normal condition not found on the load schedule.

Typically the load schedule is designed to minimize thermal stresses during normal power changes at the hottest points in the plant (e.g. reactor outlet). One approach to accomplishing this is based on the principle that the temperature change from inlet to outlet in a heat exchanger remains constant when mass flow rates on both sides and power are varied in the same proportion. This is true for ideal-like gases such as helium, hydrogen, oxygen, and nitrogen and for the liquid and gas phases of water. A second principle is that the plant transient response consists of a quasi-static component and a dynamic component that dies away in the time asymptote. By purposefully seeking to manage flow rates so they are proportional to power throughout the plant, one is assured that to the first order temperatures will remain constant. This is the approach used to design the plant control system in this work.

\section{B. Power Conversion Unit}

Additional control requirements beyond managing temperature rates of change exist for the Power Conversion Unit (PCU). 


\section{B.1 Inventory Control}

It is assumed in this work that the PCU shaft speed is to remain constant during at-power operation. The basis is the constant frequency of the electric grid and the desire to avoid the added cost of frequency conversion hardware at the generator. There is an operating requirement for the turbomachines that gas velocity be proportional to blade speed to maintain velocity triangles so that high efficiency is obtained over all power. To achieve these requirements simultaneously helium inventory control is used in the PCU. Because density is proportional to pressure for fixed temperature, by varying pressure and maintaining constant speed turbomachinery, gas velocity remains constant and mass flow rate (proportional to the product of density and velocity) is linear with pressure. Thus, pressure is manipulated through coolant mass inventory so that it is proportional to heat exchanger power so that in turn mass flow rate is proportional to heat exchanger power.

\section{B.2 Turbine Bypass Control}

In the PCU during rapid transients the rate at which inventory must be changed according to the load schedule may not be physically achievable. The helium fill and bleed system has limited capacity. In this case turbine bypass control is used to more quickly vary the power output of the shaft. In this scheme the power output of the turbine is changed by bypassing high pressure compressor outlet coolant to the exit of the turbine. The pressure drop across the turbine is reduced so power is reduced while at the same time the frictional losses through the rest of the PCU circuit increase. The result is a rapid reduction in shaft power. However, PCU efficiency is reduced under turbine bypass control and so control is typically transitioned back to inventory control over time.

\section{Primary System}

There is no hard requirement for constant speed operation of the compressor in the primary system. If one chooses to run at constant speed, then inventory control is used to maintain high efficiency. If variable speed is used, then inventory is maintained constant to remain near the peak efficiency point of the compressor.

\section{High Temperature Steam Electrolysis Plant}

The electrolyzer full power operating point in this work is taken from [7]. In the operating mode selected the cell is run adiabatically with a current density is $0.45 \mathrm{amp} / \mathrm{cm}^{2}$. There is a net production of sensible heat giving rise to an increase in temperature from inlet to outlet. The heat is recuperated by a heat exchanger at the exit of the cell and is used to heat the incoming reactants.

Operation at partial hydrogen production rates is carried out to maintain a constant cell temperature rise over the hydrogen production range. Since the rest of the HTE plant is run to maintain a constant cell inlet temperature, then the cell outlet temperature will remain constant over the hydrogen production range. To achieve the constant temperature rise, the electrical 
work should be proportional to flow rate which is proportional to current for fixed inlet and outlet mole fractions

$$
W=\dot{m}=K I
$$

where $\dot{m}$ is water mass flow rate, $K$ is a proportionality constant, and $I$ is current. But

$$
W=V_{\text {cell }} A i=V_{\text {cell }} I
$$

where $A$ is cell area and $i$ is current density. The above two equations require that $V_{\text {cell }}$ be constant. But

$$
V_{\text {cell }}=V_{N}+i A S R
$$

where $A S R$ is the area specific resistance and $V_{N}$ is the Nernst voltage and constant because inlet and outlet mole fractions remain fixed. Thus $i$ must be constant over the production range. But since $i=I / A$ where $I$ is already proportional to mass flow rate, then $A$ must also be proportional to flow rate (to realize constant $i$ ). If the cell inlet temperature and pressure remain fixed, then

the net temperature rise (as a consequence of ohmic heating and reaction enthalpy change) will be independent of hydrogen production rate. Then the cell outlet temperature will remain constant with hydrogen production rate. In summary then the cell should be run with cell area and current both proportional to hydrogen production rate.

The load schedule should implement the above specifying the value of all process variables in terms of fraction of full power hydrogen production rate.

\section{RESULTS}

A series of transients was simulated to evaluate plant control strategies and to assess control system performance. Specific items investigated were 1) how effectively are hot side temperatures maintained constant over the normal operating range during quasi-static load change, ramp load change, and step load change, 2) how stable is the closed-loop plant response, and 3) how inherently stable is the reactor (i.e. without a control system shaping response) during change or loss of load?

The simulations were performed with the G-PASS code and included the following models. A model for the electrolytic cell validated previously against INL results and described in [8]. Turbo-machine performance curves for efficiency and enthalpy rise as a function of mass flow rate and speed. These curves are described in [9]. A multi-node model for the Printed Circuit Heat Exchanger that uses NIST property data was used for the IHX and recuperator. The validation of this model against RELAP is described in [10]. The simulations included a reactor model that provides multiple coolant channels, multiple axial nodes, and region-specific worth tables. In this work the model was run with a single channel and with a single axial node. Point kinetics and reactivity feedbacks described in [11] were used. The decay heat curves used are described in [12]. 


\section{A. Load Schedule}

The values of plant process variables for steady-state hydrogen production rates between 75 and 100 percent of full power are given by the load schedule reported here. The objective in designing this schedule was to achieve near constant hot side temperatures in both the nuclear and chemical plants. The control strategy used to achieve this is that of Section IV. Briefly, mass flow rates are maintained proportional to power throughout, inventory control is used in the PCU, and electrolytic cell area and current are maintained proportional to hydrogen production rate.

The temperatures in the HTE plant are shown in Figure 5. The overall trend is that the highest temperatures are essentially constant over the hydrogen production range. The maximum variation in any of these individual temperatures is $20 \mathrm{C}$. It may possible to reduce this variation through a more detailed design effort. The present design assumes flow rates proportional to hydrogen production rate and does not take into account nonlinear dependencies between components. Further, in the HTE plant and its process heat loop there are a total of five compressor and pumps that can be independently controlled. A means of making use of this flexibility to achieve flat temperatures is described by Vilim in [13].

The temperatures in the hot and cold side of the NGNP are shown in Figure 6 and 7, respectively. The temperature variation on the hot side is less than $20 \mathrm{C}$.

Helium loop pressures are shown in Figure 8. Pressure is to a first order proportional to hydrogen production rate, a consequence of inventory control. The production and consumption of power by major system components is shown in Figure 9. Essentially all the thermal power produced by the NGNP is consumed by thermal loads in the HTE plant and in generating electricity to power electrical loads which include the electrolyzer and pumps and compressors.

\section{B. Inherent Response}

The inherent or open-loop response of the reactor is of interest for two reasons. First, the plant control system operates to modify the plant open-loop response so that variables track setpoints in response to changes in load. This is achieved by introducing new feedback paths via connections between sensors and actuators. To guide design of the control system and to avoid undo complexity the open-loop response of the plant needs to be understood. Second, the safety case for the plant can take no credit for operation of the plant control systems. Instead the inherent feedbacks associated with reactivity temperature coefficients and turbomachine characteristics are relied upon to provide a safe open-loop response to upsets. 


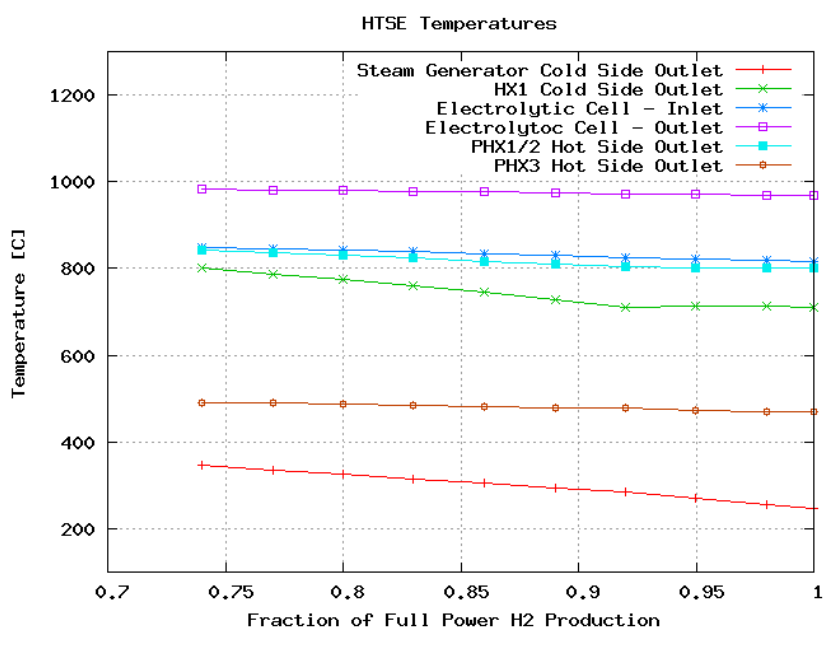

Figure 5 Load Schedule for Reference Interface - HTE Temperature

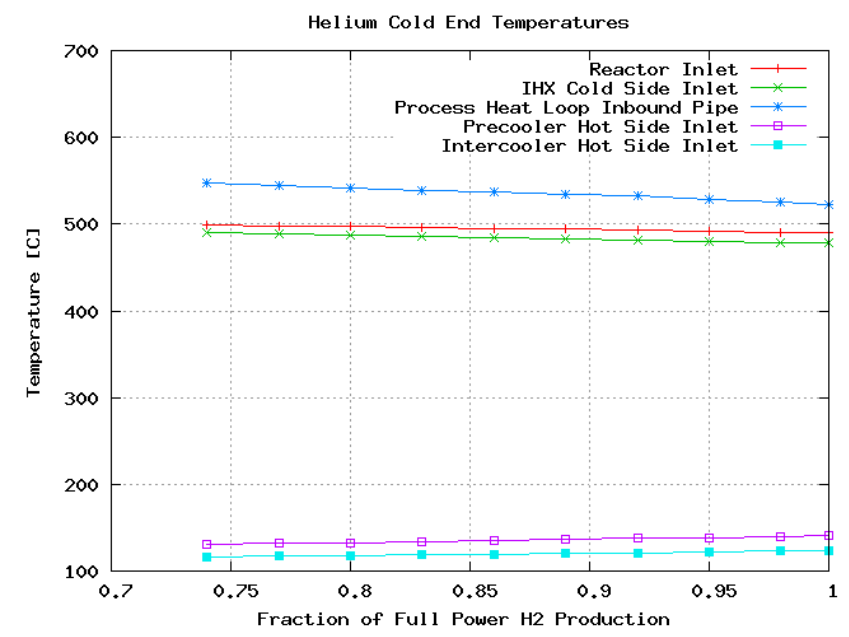

Figure 7 Load Schedule for Reference Interface - Cold Side Helium Temperatures

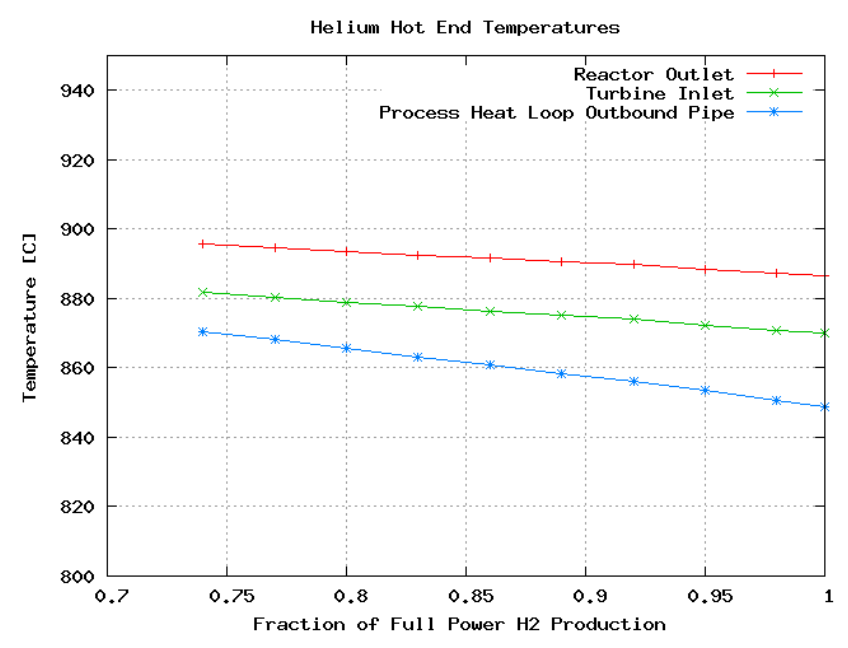

Figure 6 Load Schedule for Reference Interface - Hot Side Helium Temperatures

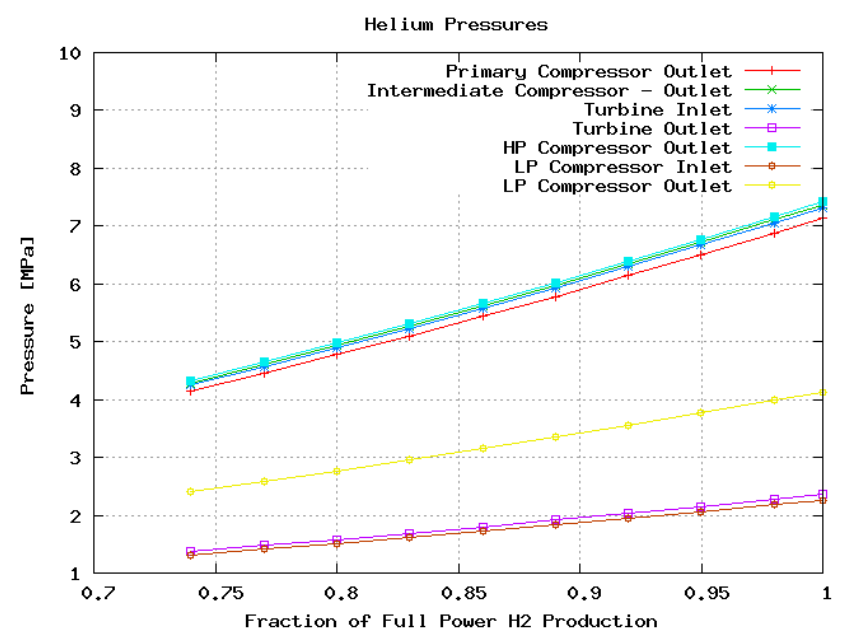

Figure 8 Load Schedule for Reference Interface - Helium Pressures 


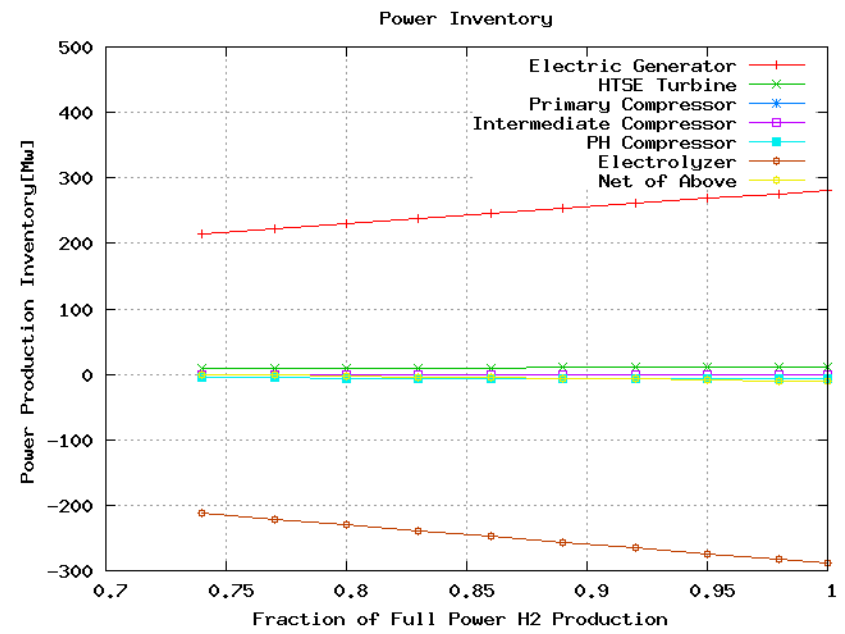

Figure 9 Load Schedule for Reference Interface - Component Powers

The open-loop response characteristics of the reactor are a function of several factors. These include the manner in which core neutronic power depends on temperature reactivity feedbacks, the manner of the coupling of the core to the ultimate heat sink, and the time taken for a perturbation in core outlet temperature to propagate back to the inlet of the core.

The time delay for reactor outlet temperature perturbations to return back to the reactor inlet has three components. They are, starting at the reactor outlet, the circulation time around the primary system, the circulation time out through the IHX and through the PCU and the return back through the IHX, and a similar circulation path through the IHX but this time through the hydrogen process heat loop. With all three time lags acting simultaneously, the role attributable to each of these paths in the integrated plant behavior is somewhat obscured. A clearer picture is obtained by introducing a simplified representation. A single time lag between the core outlet and inlet captures the essence of all three components. A measure of stability is obtained by varying this parameter and observing the tendency for outlet temperature and power time variations to be naturally damped.

The behavior of the plant configuration shown in Figure 10 was used to investigate the role of the time delay. This configuration contains the features that are important for evaluating the role of this delay including the primary system, the intermediate heat exchanger, and a heat sink. In a G-PASS simulation the inlet to the cold side of the heat exchanger was driven by a temperature forcing function that represents a perturbation assumed to originate in the PCU or HTE plant. The perturbation upon reaching the heat exchanger passes through it, moves on to the core, and on passing through the core perturbs the reactor outlet temperature. This perturbation can make 
its way back to the core through any of the three different paths described above. Each has a characteristic time. A single mixing volume shown in Figure 10 between the core outlet and the inlet to the hot side of the heat exchanger is used to represent the associated delay.

In addition to the transport time delay, other phenomena important for reactor-heat sink dynamic behavior were included in the simulation. These include 1) the storage of mass and energy in the coolant in the core channels and the hot and cold sides of the intermediate heat exchanger. 2) The storage of energy in the fuel and graphite with related data used in the simulation is given in Table II. 3) Reactivity as a function of temperature with related data used in the simulation given in Tables III, IV, and V. 4) A six-group point kinetics model driven by individual temperature feedback components.

Simulations were performed for a near-step increase in temperature at the inlet to the cold side of the intermediate heat exchanger. The forcing function is shown in Figure 11. The magnitude of the temperature increase resulted in an asymptotic decrease in core power of $50 \mathrm{MWt}$ without active reactivity addition (i.e. control rod movement) which equals the full power heat input to the HTE plant. The temperature increase was purposely selected to correspond to a complete loss of the HTE plant as a heat sink. The results for a $20 \mathrm{~s}$ mixing volume time constant appear in Figure 12 through 16. The coolant, graphite, and fuel average temperature are shown in Figure 12. The reactivity components are shown in Figures 13. The reactor power appears in Figure 14. The outlet temperature of the core and of the mixing volume is shown in Figure 15. Figure 16 shows the change in core outlet temperature versus change in core inlet temperature. The inherent stability of the reactor is reflected in the change in reactor outlet temperature versus the change in reactor inlet temperature. The reactor response is considered stable if the outlet temperature is damped and in-phase with the inlet temperature.

The potential for instability was investigated across a broad range of outlet-to-inlet transport delays. Simulations of the NGNP response to the forcing function in Figure 11 were performed for mixing volume time constant values of 5, 50, and $500 \mathrm{~s}$. Figure 17 shows the change in core outlet temperature versus change in core inlet temperature for these three values. The corresponding inherent power response (i.e. not control rod motion) appears in Figure 18.

The dynamic simulation results indicate temperature perturbations originating in the HTE plant will not give rise to unstable reactor behavior. Instead, the reactor response is very stable. Figure 17 shows that in the long term the reactor outlet temperature reverts back to its original value before a step change in cold side IHX inlet temperature was imposed. In the short term, Figure 17 shows the temperature perturbation at the core inlet is attenuated by at least a factor of two in passing through the core and that the resulting perturbation exiting the core is almost completely attenuated by the IHX before return to the core inlet. This is true for delay times of five through 500 seconds. Figure 18 shows the core power is essentially unaffected by the size of the delay. Thus, sustained out-of-phase oscillations between core inlet and outlet temperature do not appear likely in the NGNP/HTE at full power conditions for nominal values of reactivity feedback coefficients. A large Doppler reactivity component, three times greater than next reactivity component per unit temperature, is mainly responsible. Future work should investigate the sensitivity of this result to variation in the values of reactivity feedback parameters and for partial power conditions, particularly at low mass flow rates. 
Table II Values of Design Parameters for Annular Unit-Cell Representation of Fuel Element.

\begin{tabular}{|c|c|c|c|c|c|c|c|}
\hline \multirow[t]{2}{*}{ Coolant } & $n_{c l}$ & $\begin{array}{c}A_{c l} n_{c l} \\
\left(\mathrm{~m}^{2}\right)\end{array}$ & $\begin{array}{c}A_{c l} \\
\left(\mathrm{~m}^{2}\right)\end{array}$ & $\begin{array}{c}r_{c l} \\
(\mathrm{~m})\end{array}$ & $\begin{array}{c}C_{p-c l} \\
(\mathrm{j} / \mathrm{kg}-\mathrm{C})\end{array}$ & $\begin{array}{c}k_{c l} \\
(\mathrm{w} / \mathrm{m}- \\
\mathrm{C})\end{array}$ & - \\
\hline & 106 & $102 \frac{\pi}{4} 0.016^{2}=0.022$ & $\begin{array}{c}2.1 \mathrm{E}- \\
04\end{array}$ & $\begin{array}{c}26 \mathrm{E}- \\
03\end{array}$ & 5200 & 0.37 & \\
\hline \multirow[t]{2}{*}{ Graphite } & 106 & $\begin{array}{l}A_{g r} n_{c l} \\
\left(\mathrm{~m}^{2}\right)\end{array}$ & $\begin{array}{l}A_{g r} \\
\left(\mathrm{~m}^{2}\right)\end{array}$ & $\begin{array}{l}r_{g r} \\
(\mathrm{~m})\end{array}$ & $\begin{array}{c}C_{p-g r} \\
(\mathrm{j} / \mathrm{kg}-\mathrm{C})\end{array}$ & $\begin{array}{c}k_{g r} \\
(\mathrm{w} / \mathrm{m}- \\
\mathrm{C})\end{array}$ & $\begin{array}{c}\rho_{g r} \\
\left(\mathrm{~kg} / \mathrm{m}^{3}\right)\end{array}$ \\
\hline & & $\begin{array}{c}\sqrt{ } 3(0.360)^{2}-0.022- \\
0.027=0.175\end{array}$ & $\begin{array}{c}1.7 \mathrm{E}- \\
03\end{array}$ & $\begin{array}{c}25 \mathrm{E}- \\
03\end{array}$ & 1100 & $80 / 9.0 *$ & 1,740 \\
\hline \multirow[t]{2}{*}{ Fuel } & 106 & $\begin{array}{l}A_{f} n_{c l} \\
\left(\mathrm{~m}^{2}\right)\end{array}$ & $\begin{array}{c}A_{f} \\
\left(\mathrm{~m}^{2}\right)\end{array}$ & $\begin{array}{l}r_{f} \\
(\mathrm{~m})\end{array}$ & $\begin{array}{c}C_{p-f} \\
(\mathrm{j} / \mathrm{kg}-\mathrm{C})\end{array}$ & $\begin{array}{c}k_{f} \\
(\mathrm{w} / \mathrm{m}- \\
\mathrm{C})\end{array}$ & $\begin{array}{c}\rho_{f} \\
\left(\mathrm{~kg} / \mathrm{m}^{3}\right)\end{array}$ \\
\hline & & $210 \frac{\pi}{4} 0.0127^{2}=0.027$ & $\begin{array}{c}2.5 \mathrm{E}- \\
04\end{array}$ & $\begin{array}{c}8.9 \mathrm{E}- \\
03\end{array}$ & $\begin{array}{c}160 \\
\left(C p_{U C_{2}} \sim C p_{U C}\right)\end{array}$ & $\begin{array}{c}20 / 80^{*} \\
\text { (UC) }\end{array}$ & 13,600 \\
\hline
\end{tabular}

* Conductivity values given were subsequently revised to reproduce fuel temperatures reported in NGNP project Point Design document. Revised values appear on right side.

Table III Upper Bound for Differential Worth of Operating Control Rods for GT-MHR

\begin{tabular}{|c|c|}
\hline Number of Operating Control Rods ${ }^{\mathrm{a}}$ i.e., outer neutron control & 36 \\
\hline Upper limit on worth per $\operatorname{rod}^{\mathrm{b}}(\$)$ & 0.5 \\
\hline Absorber length of Operating Control $\operatorname{Rod}^{\mathrm{c}}$ (in/m) & $229 / 5.8$ \\
\hline Worth per absorber per unit absorber length $(\$ / \mathrm{m})$ & $0.5 / 5.8=0.086$ \\
\hline $\begin{array}{l}\text { Combined worth of Operating Control Rods per unit absorber length } \\
(\$ / \mathrm{m})\end{array}$ & $0.086(36)=3.1$ \\
\hline
\end{tabular}

${ }^{a}$ Startup control rods are withdrawn before criticality: p.4-5 and p. 4-12 of [14].

Operating control rods are inserted to varying heights during operation: p.4-22 of [14].

${ }^{b}$ Each control rod has its own independent drive: p.4-26 of [14]. Any single drive, for

safety reasons, should be limited to less then one dollar.

${ }^{\mathrm{c}}$ Figs. 4.1-12, 4.1-13, and 4.2-2 [14]. Scaled from these figures. 
Table IV Derivation of Control Rod Reactivity Coefficients for VHTR

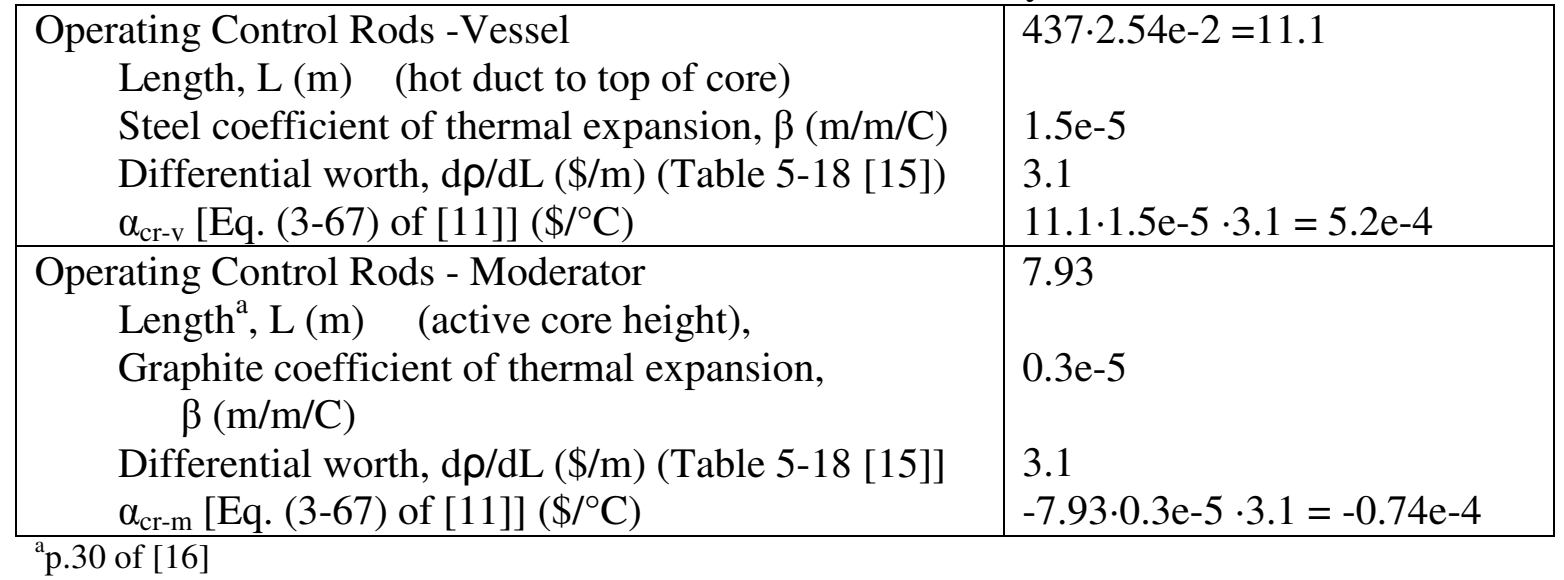

Table V Integral Reactivity Coefficients for VHTR

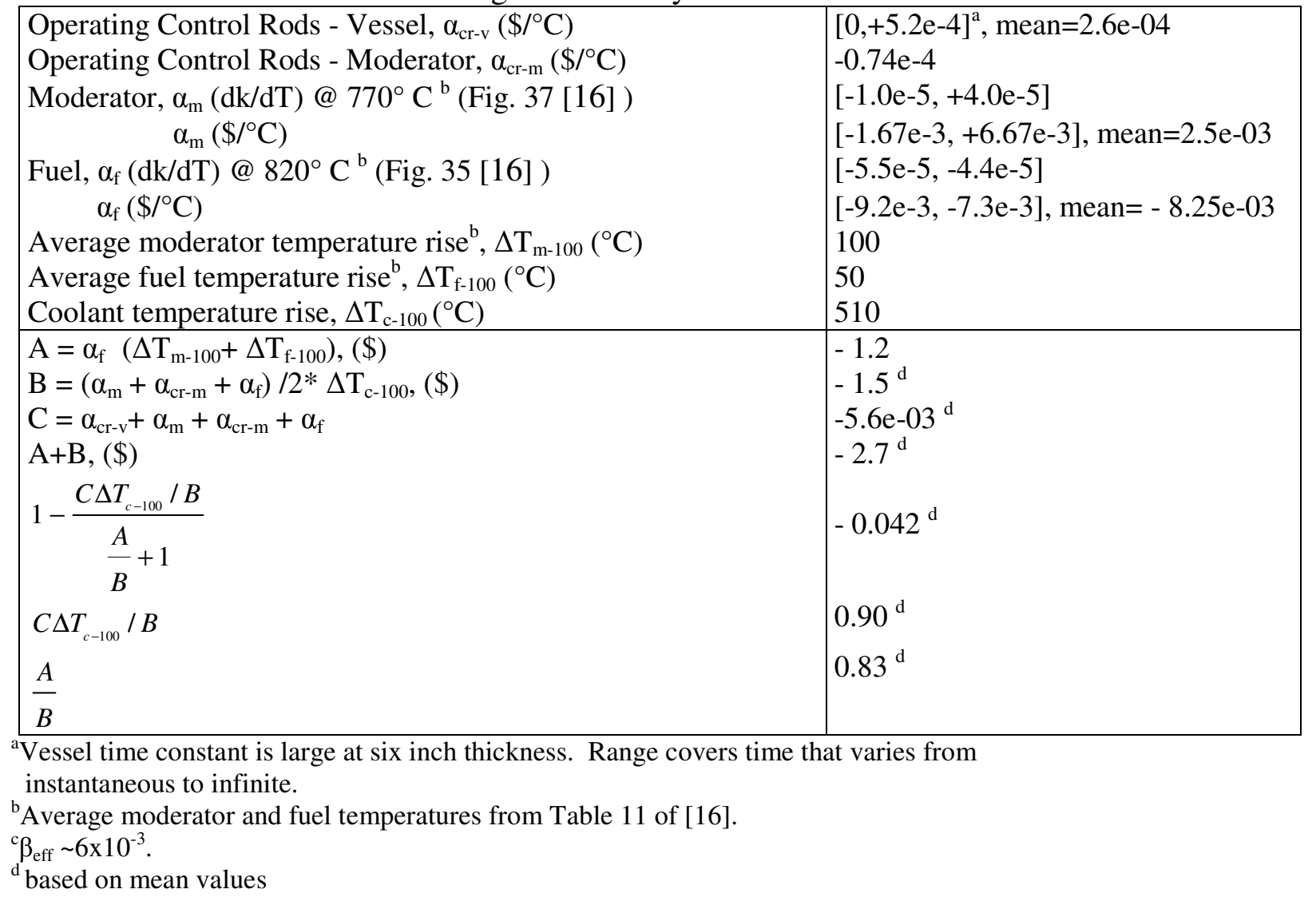


Propagation of $\mathrm{H}_{2}$ Plant Temperature Disturbance in Combined Plant

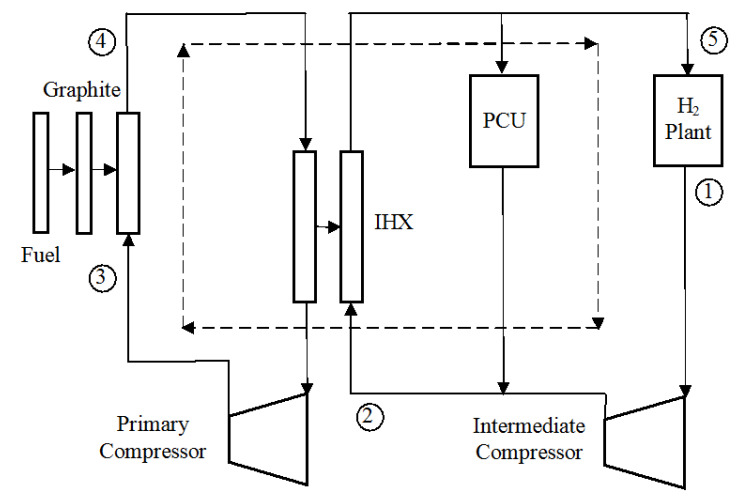

Points along Path of Propagation

(1) Initial temperature perturbation

(2) Perturbation enters IHX

(3) Perturbation enters core

(4) Phased-lagged perturbation exits core

(5) Perturbation returns to $\mathrm{H} 2$ plant

Path Delay with Potential to Create Instability (4) - (5) - (1) - (2) - (3)
Canonical Representation of Combined Plant with Surrogate Path Delay

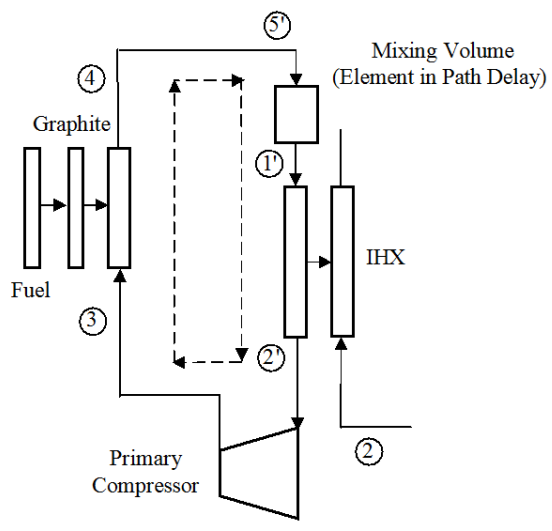

Surrogate Path Delay for Investigation of Stability

(4) - (5) - (1) - (2) - (3)

Figure 10 Plant Configuration for Assessment of Combined-Plant Stability

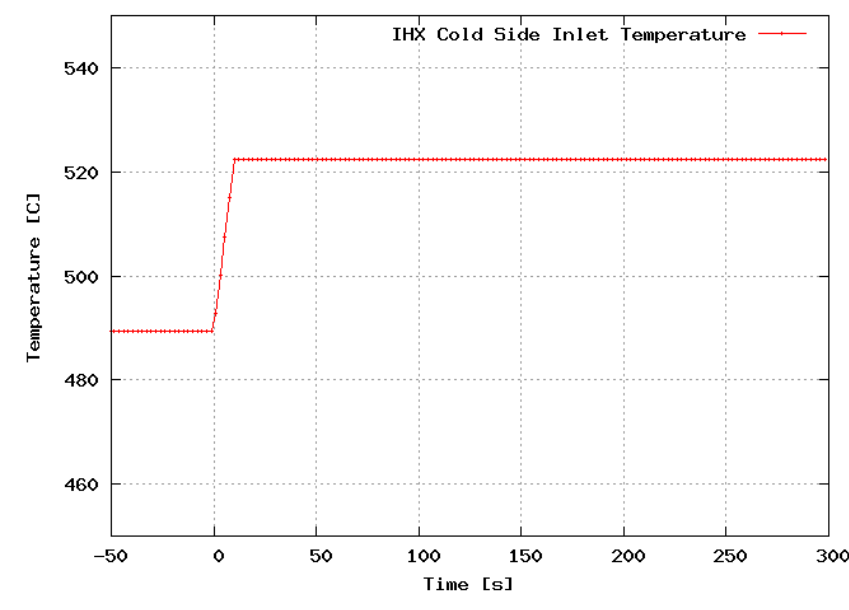

Figure 11 Loop Reactor Response to Intermediate System Temperature Perturbation - Forcing Function

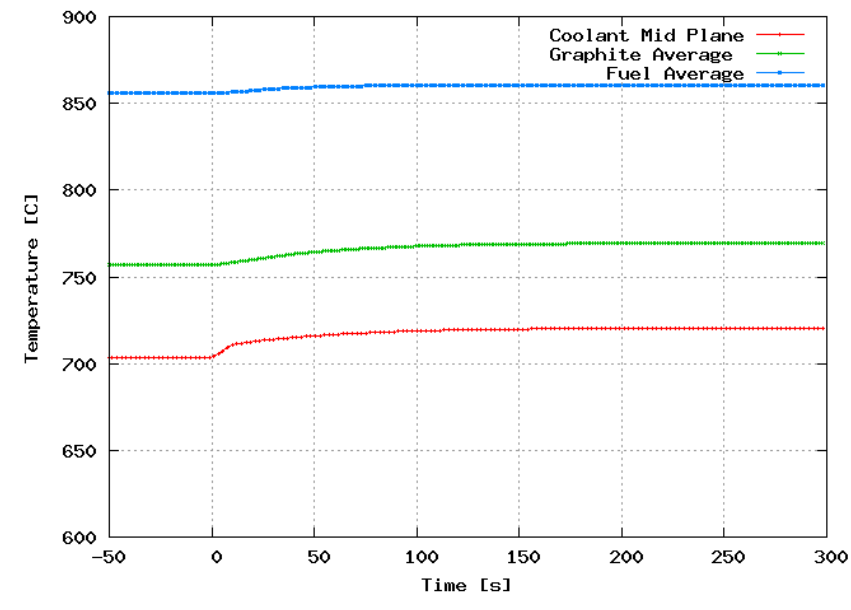

Figure 12 Loop Reactor Response to Intermediate System Temperature Perturbation - Core Temperatures. Mixing Time Constant of $20 \mathrm{~s}$ 


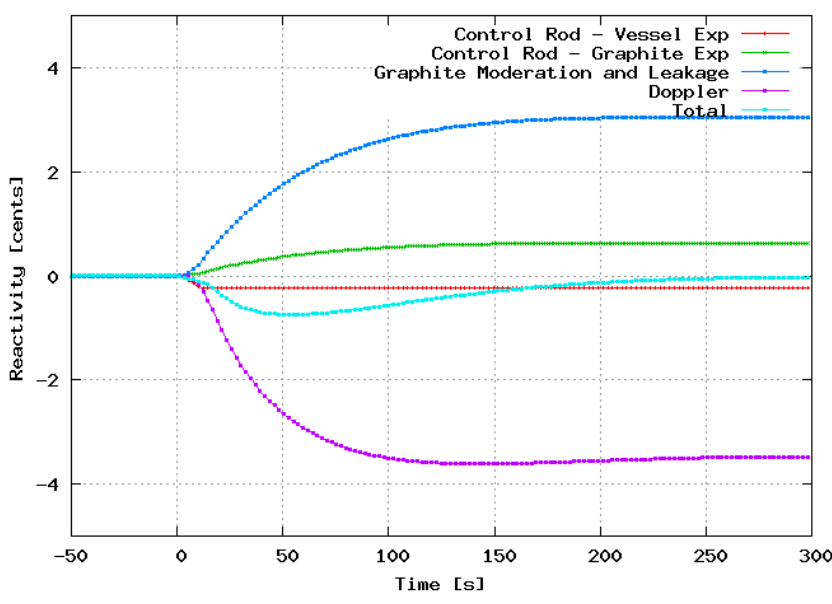

Figure 13 Loop Reactor Response to Intermediate System Temperature Perturbation - Reactivity Components. Mixing Tim Constant of $20 \mathrm{~s}$

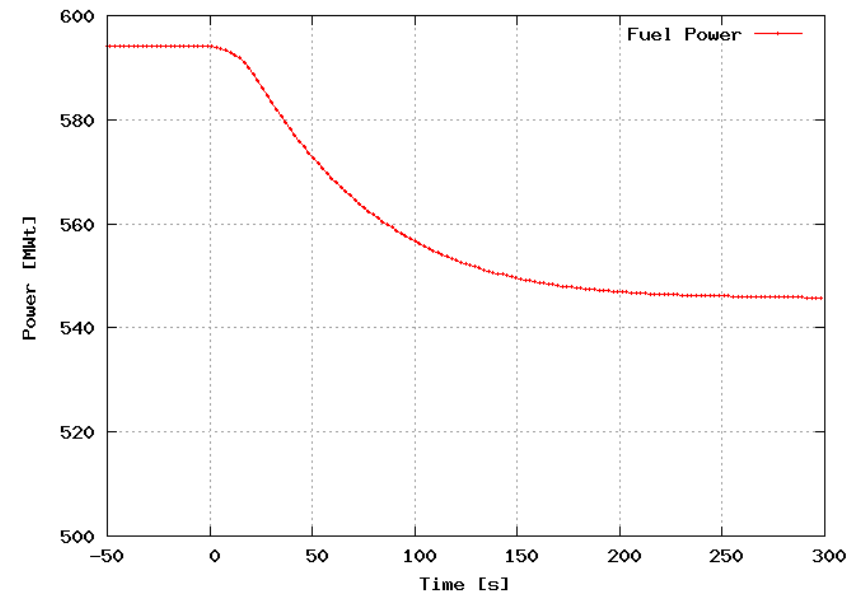

Figure 14 Loop Reactor Response to Intermediate System Temperature Perturbation - Fuel Thermal Power. Mixing Time Constant of $20 \mathrm{~s}$

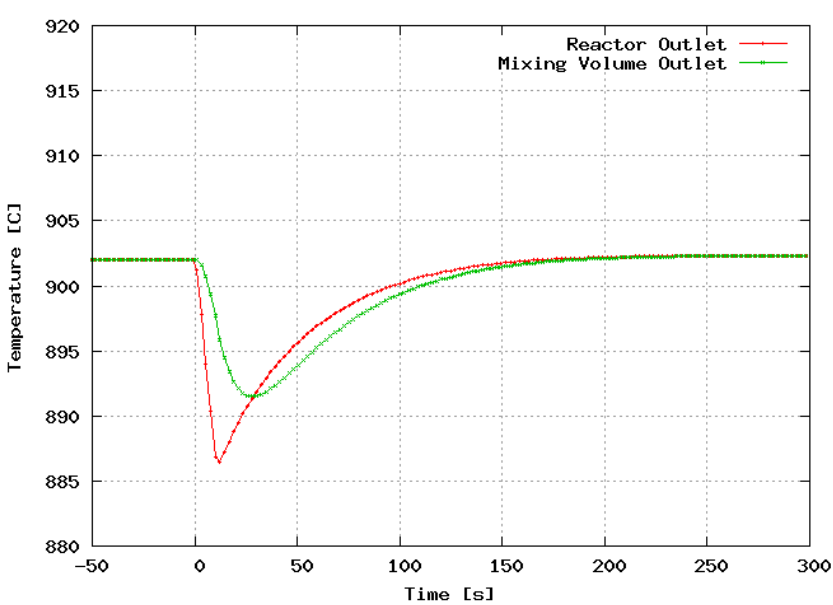

Figure 15 Loop Reactor Response to Intermediate System Temperature Perturbation - Outlet Temperature. Mixing Time Constant of $20 \mathrm{~s}$

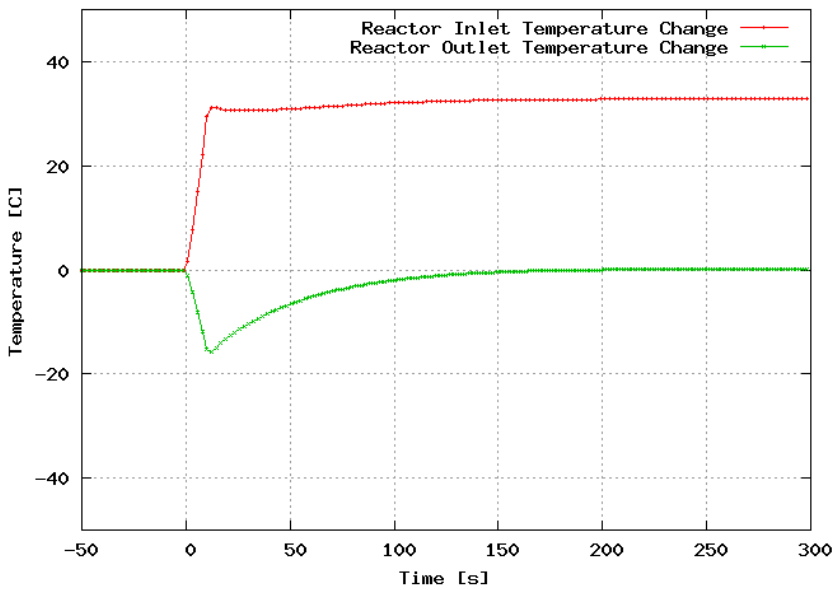

Figure 16 Loop Reactor Response to Intermediate System Temperature Perturbation - Reactor Temperature Change. Mixing Time Constant of $20 \mathrm{~s}$ 


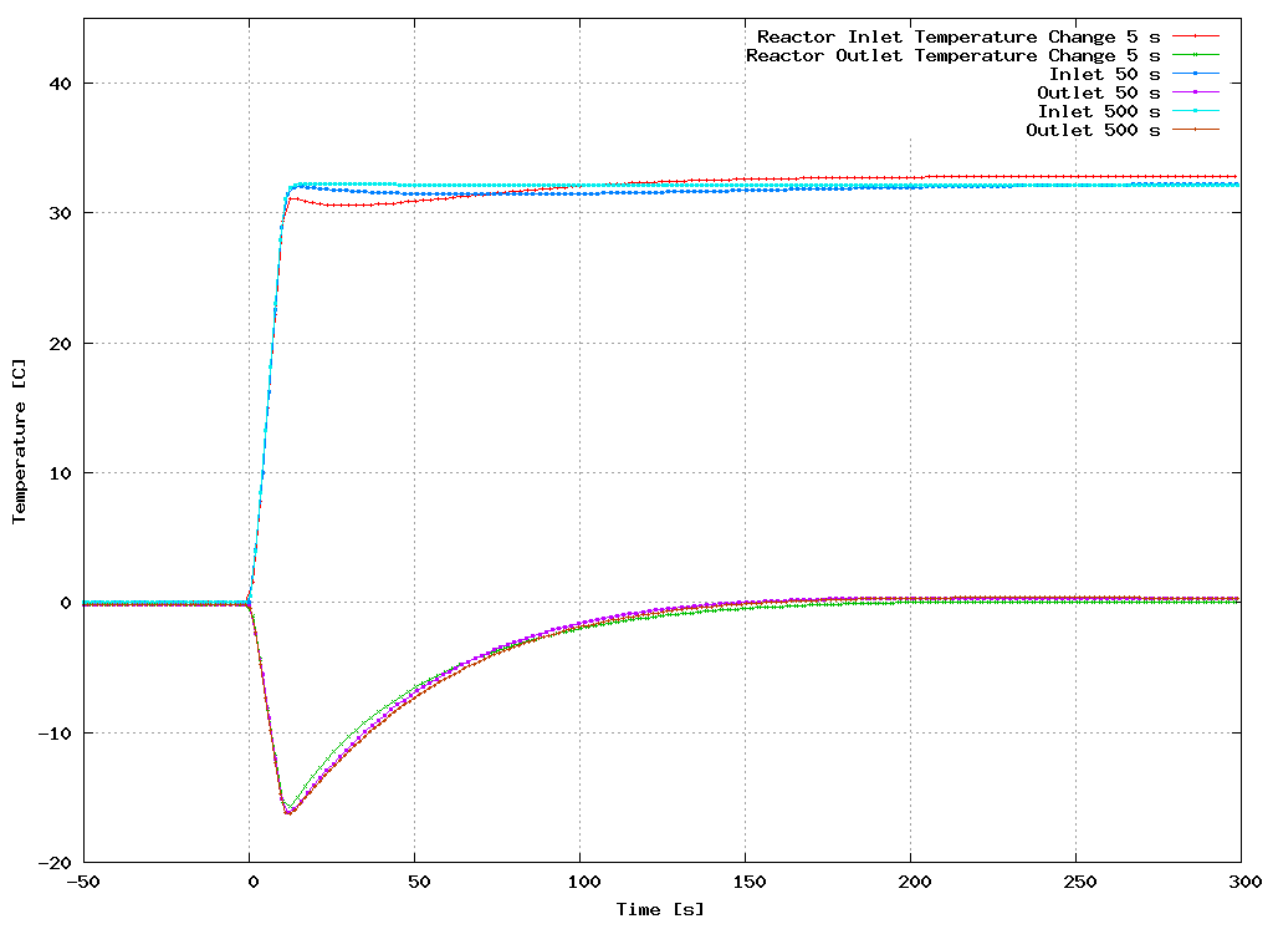

Figure 17 Change in Core Inlet and Outlet Temperatures as a Function of Mixing Time Constant

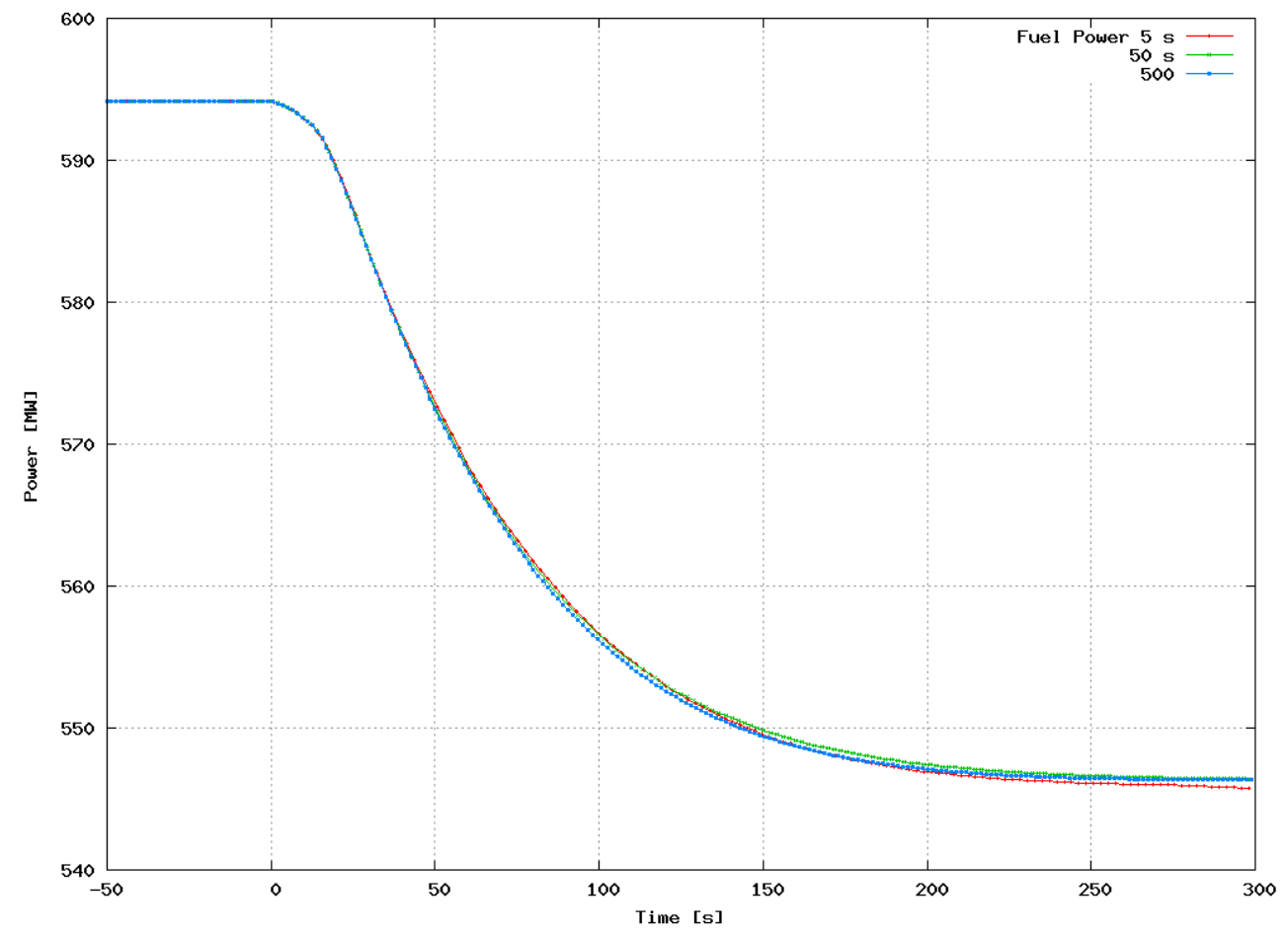

Figure 18 Power in Fuel as a Function of Mixing Time Constant 
An important control objective in a nuclear reactor is to maintain constant reactor outlet temperature during load change. A typical controller senses outlet temperature, computes the error compared to the desired or setpoint temperature, and then adjusts reactor power based on the size of the error to drive the outlet temperature to the setpoint value. However, this control system introduces a new feedback path and potentially can alter the stability characteristics of the reactor. This is investigated below.

The behavior of the NGNP reactor operating with the Reactor Outlet Temperature Controller described above was investigated using the G-PASS code. This simulation involved the fuel, moderator, and coolant channel. The proportional-integral controller described above operates to maintain constant reactor outlet temperature. In the simulation the reactor fuel thermal power was changed directly. In practice a lower level controller would be needed to adjust rod position to provide the corresponding reactivity. In the simulation the inlet temperature to the reactor is a forcing function whose value is perturbed from the steady-state. The reactor outlet temperature response was investigated for a range of controller parameter values. We were unable to find a set of values that gave rise to an over-damped response. A typical stable response is that which shows decaying oscillations that tend toward an asymptotic steady-state temperature.

This simple simulation suggests that the reactor operating with the Reactor Outlet Temperature Controller is less stable than the reactor operating open-loop. It appears the feedback path introduced by the controller overrides the more stable response observed when the reactivity feedbacks operate alone. The behavior of the indirect cycle NGNP plant with this controller in place is investigated below.

\section{Change in Electric Generator Load}

The plant dynamic response to changes in generator load was investigated. In the reference interface design approximately $550 \mathrm{MW}$ of the total $600 \mathrm{MW}$ reactor thermal output is delivered to the PCU for electricity production. The remaining $50 \mathrm{MW}$ is delivered to the HTE plant through the high temperature process heat exchanger. The HTE plant and nuclear plant therefore interface mainly at the electric generator. In the simulations that follow we make the simplifying assumption that the HTE plant interfaces with the NGNP only at the generator. The high temperature process heat loop is not modeled. The HTE plant electrical power demand is modeled as a generator load forcing function that drives the PCU of the NGNP. The timevarying hydrogen production demand the HTE plant is assumed to have to meet is taken as step changes of ten percent and ramp changes of three percent per minute. Since hydrogen production rate is proportional to electric power consumption, it follows that at the generator the NGNP PCU must be able to meet a ten percent step change and a three percent per minute change in electric power generation. The NGNP response for these demand changes is described below. 


\section{C.1 Ramp of Three Percent per Minute}

The NGNP response is described for a three percent per minute ramp in electric power generation. The forcing functions driving this transient are shown in Figure 19. The generator load is decreased from an initial steady state of 100 percent power down to 50 percent power over $1000 \mathrm{~s}$. The precooler and intercooler water flow rates are also decreased to 50 percent. The neutronic/decay power shown is that which results from the action of the Reactor Outlet Temperature Controller as described below. (Note: The neutronic/decay power was included in Figure 19 for ease of comparison with other important variables. Contrary to the figure caption neutronic/decay power was not a forcing function.) The plant control system is identified in Table VI (control systems A and B) with individual controllers described in Tables VII and VIII.

The plant control system was designed with several objectives in mind. First, reactor outlet temperature was to be maintained at $850 \mathrm{C}$ using the Reactor Outlet Temperature Controller described above. Second, to minimize thermal stresses in the IHX, the flows on the hot and cold side of the IHX are maintained near equal over the course of the transient. To accomplish this primary system inventory is adjusted by a PI controller to force the differential between primary and PCU flow rate to track a setpoint of near $0 \mathrm{~kg} / \mathrm{s}$. Third, to maintain high PCU efficiency in the presence of a changing electric generator load (forcing function) inventory control is used. Additional details are provided in Section IV.B.1. Inventory is adjusted by a PI controller to force shaft speed to track a constant setpoint of $60 \mathrm{~Hz}$. Fourth, cooler powers are adjusted (via cold side flow rates) for heat removal consistent with PCU operation under inventory control. This essentially means that heat rejection should scale with shaft power.

Simulations for the transient with generator electric load changed at three percent per minute showed oscillations with a period of 200 s superimposed on what is essentially the quasi-static response from the load schedule. The oscillations decay very slowly, over a period of several thousand seconds. To test the hypothesis that these oscillations arise with operation of the Reactor Outlet Temperature Controller, the simulation was repeated but with the mass and energy storage in the reactor becomes zero. With no storage, any phase lag introduced by fuel, moderator, and coolant time constants is set to zero. The NGNP response for this transient is shown in Figures 20 through 24. Figure 20 and 21 show the inventories and mass flowrates in the primary system and PCU, respectively. They are halved over the course of the transient which is consistent with operation under inventory control. The temperatures in the IHX shown in Figure 24 are very nearly constant as was our design objective.

The oscillations referred to above are not present in Figure 20 through 24 suggesting that they were indeed induced by the Reactor Outlet Temperature Controller interacting with mass and energy storage mechanisms in the core. It appears that a controller more sophisticated than a PI controller may be needed to achieve acceptable reactor outlet temperature regulation for load changes. A stability analysis should be conducted to investigate the sensitivity of oscillations to reactor nodalization and to characterize the role of energy storage mechanisms in the core. 
Table VI Operating Mode and Associated Control Systems

\begin{tabular}{|c|c|c|}
\hline Operating Mode & \multicolumn{2}{|c|}{ Plant Subsystem } \\
\cline { 2 - 3 } Ramp Change Electric Load & Primary System & PCU \\
\hline Step Change Electric Load & A & B \\
\hline
\end{tabular}

Table VII Description of Control System A Individual Controllers

\begin{tabular}{|c|l|l|l|}
\hline $\begin{array}{c}\text { Control } \\
\text { System }\end{array}$ & \multicolumn{1}{|c|}{ Controller } & \multicolumn{1}{|c|}{ Set Point Variable } & \multicolumn{1}{|c|}{$\begin{array}{c}\text { Variable Adjusted to Meet } \\
\text { Setpoint }\end{array}$} \\
\hline & $\begin{array}{l}\text { IHX Flow } \\
\text { Balance } \\
\text { Controller }\end{array}$ & $\begin{array}{l}\text { Flow differential between } \\
\text { hot and cold sides of IHX }\end{array}$ & Primary system inventory \\
& $\begin{array}{l}\text { Reactor Outlet } \\
\text { Temperature } \\
\text { Controller }\end{array}$ & $\begin{array}{l}\text { Reactor outlet } \\
\text { temperature }\end{array}$ & Reactor power \\
\hline
\end{tabular}

Table VIII Description of Control System B Individual Controllers

\begin{tabular}{|c|l|l|l|}
\hline $\begin{array}{c}\text { Control } \\
\text { System }\end{array}$ & \multicolumn{1}{|c|}{ Controller } & Set Point Variable & \multicolumn{1}{c|}{$\begin{array}{c}\text { Variable Adjusted to Meet } \\
\text { Setpoint }\end{array}$} \\
\hline & $\begin{array}{l}\text { PCU Shaft } \\
\text { Speed } \\
\text { Controller }\end{array}$ & PCU shaft speed & PCU helium inventory \\
B & $\begin{array}{l}\text { Intercooler } \\
\text { Power } \\
\text { Controller }\end{array}$ & Intercooler power & Cold side water flowrate \\
& $\begin{array}{l}\text { Precooler power } \\
\text { Precooler } \\
\text { Power } \\
\text { Controller }\end{array}$ & & \\
\hline
\end{tabular}




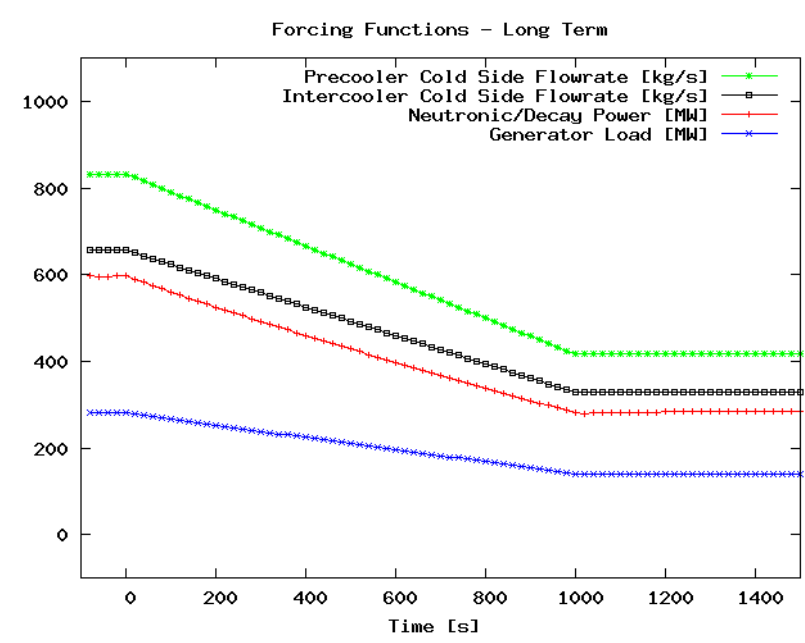

Figure 19 Ramp of Generator Load of Three Percent per Minute - Forcing Functions - Long Term

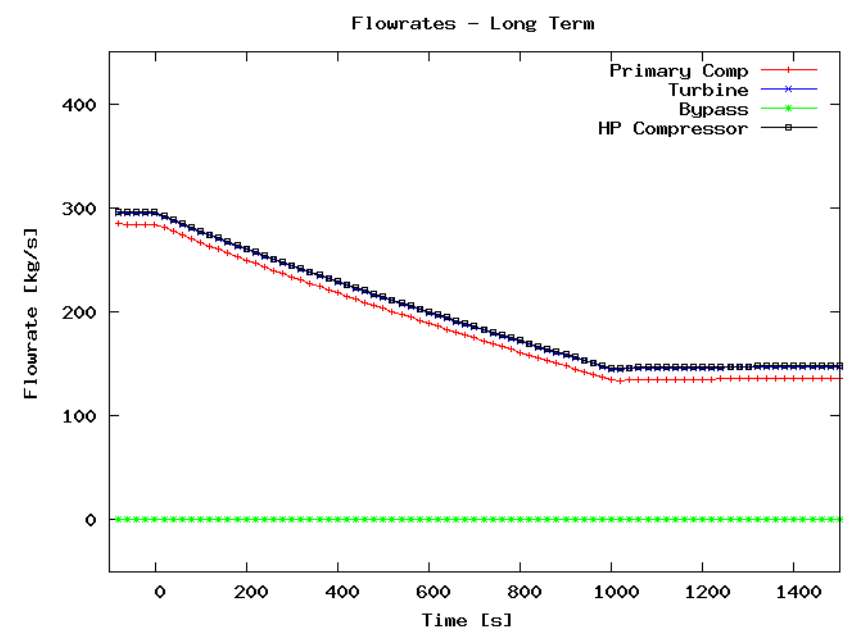

Figure 21 Ramp of Generator Load of Three Percent per Minute - Flowrates - Long Term

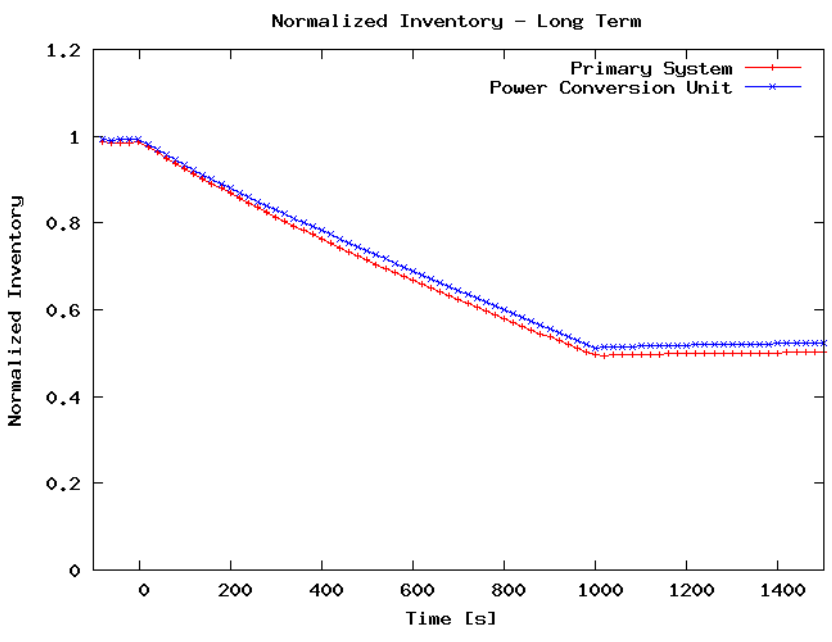

Figure 20 Ramp of Generator Load of Three Percent per Minute - Normalized Inventory - Long Term

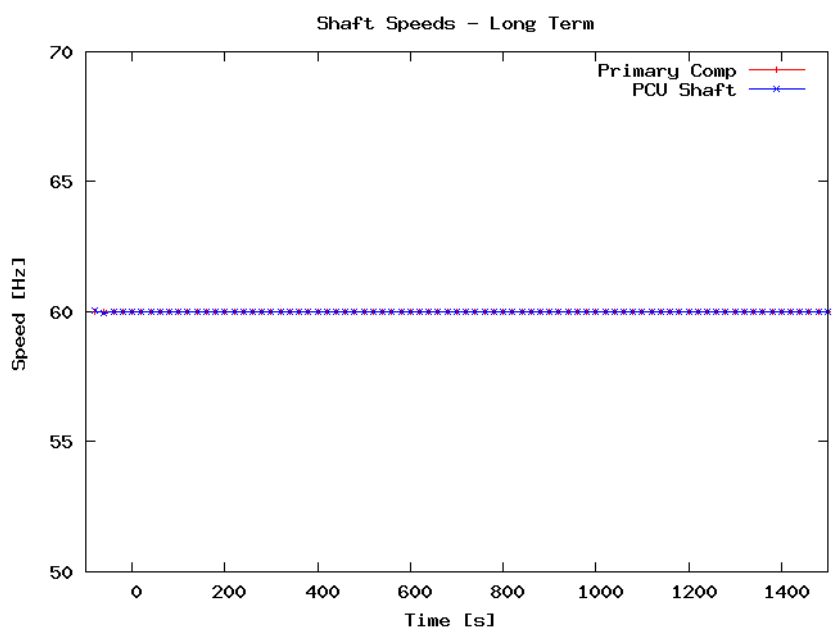

Figure 22 Ramp of Generator Load of Three Percent per Minute - Shaft Speeds - Long Term 


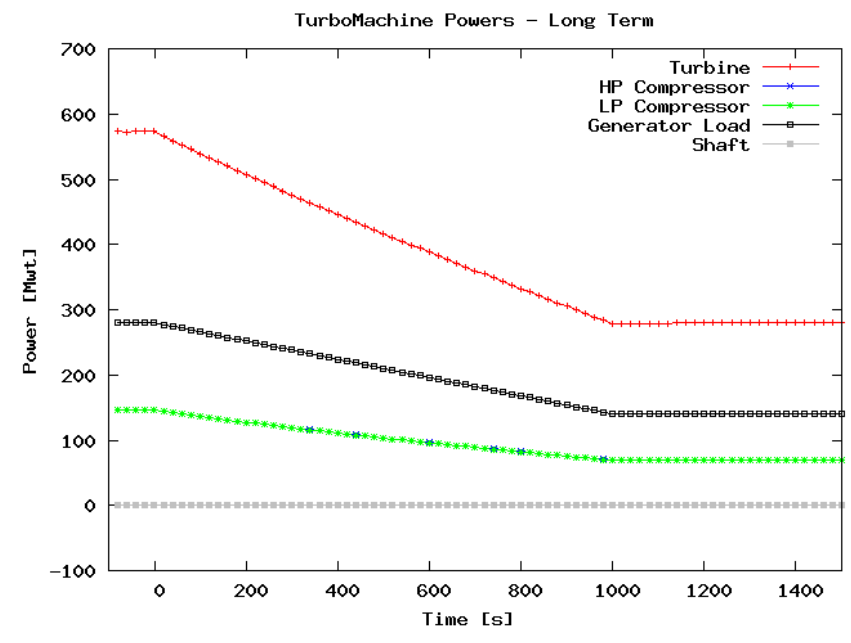

Figure 23 Ramp of Generator Load of Three Percent per Minute - TurboMachPowers - Long Term

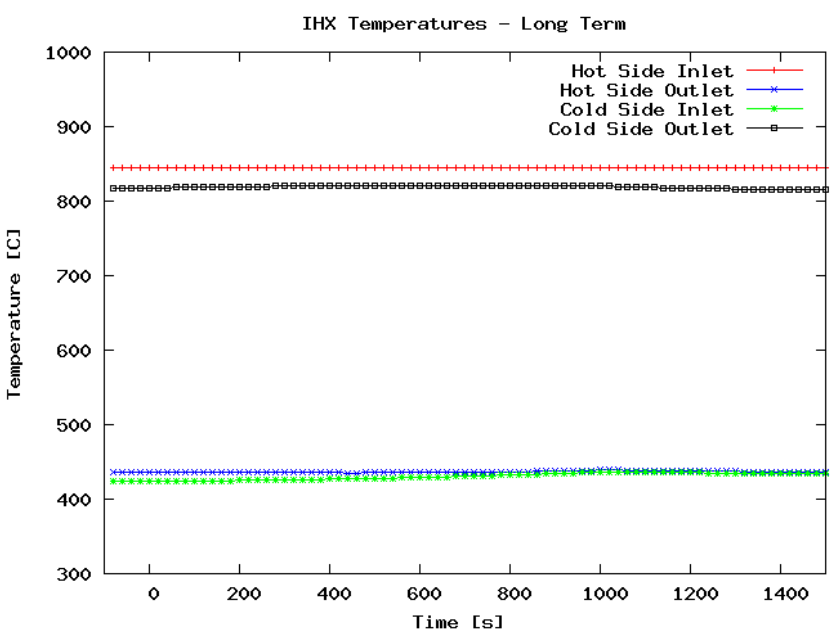

Figure 24 Ramp of Generator Load of Three Percent per Minute - IHX Temperatures - Long Term

\section{C.2 Step of Ten Percent}

Inventory control provides good temperature control as shown above and further high efficiency at partial load. But in practice its use is limited to slow changing transients. The maximum helium charge and bleed rates achievable with PCU hardware limit the rate at which inventory can be adjusted to match generator load rate of change. Turbine bypass provides a means for quickly matching PCU shaft power with a decrease in generator load. Placement of the bypass valve and line is shown in Figure 25.

A rapid ten percent reduction in generator load with bypass control was simulated. The forcing functions driving this transient are shown in Figure 26. The generator load is decreased from an initial steady state of 100 percent power down to 90 percent power over one second. The precooler and intercooler water flow rates are also decreased. The neutronic/decay power shown is that which results from the action of the Reactor Outlet Temperature Controller attempting to maintain a constant temperature. The plant control system is identified in Table VI (control systems $\mathrm{C}$ and D) with individual controllers described in Tables IX and X.

The plant response appears in Figures 27 through 37. Figure 30 shows the bypass flow rate increasing as the Bypass Flow Controller detects a mismatch between shaft speed and setpoint value of $60 \mathrm{~Hz}$. The PCU shaft speed response is shown in Figure 32. The oscillations seen in the first ten seconds are probably too large for the generator to remain connected to the grid. The amplitude can be reduced by re-tuning the PCU Shaft Speed Controller. The temperatures in the IHX shown in Figure 37 are very nearly constant as was our design objective. 
Table IX Description of Control System C Individual Controllers

\begin{tabular}{|c|l|l|l|}
\hline $\begin{array}{c}\text { Control } \\
\text { System }\end{array}$ & \multicolumn{1}{|c|}{ Controller } & \multicolumn{1}{|c|}{ Set Point Variable } & \multicolumn{1}{c|}{$\begin{array}{c}\text { Variable Adjusted to Meet } \\
\text { Setpoint }\end{array}$} \\
\hline & $\begin{array}{l}\text { IHX Flow } \\
\text { Balance } \\
\text { Controller }\end{array}$ & $\begin{array}{l}\text { Flow differential between } \\
\text { hot and cold sides of IHX }\end{array}$ & $\begin{array}{l}\text { Primary system compressor } \\
\text { speed }\end{array}$ \\
& $\begin{array}{l}\text { Reactor Outlet } \\
\text { Temperature } \\
\text { Controller }\end{array}$ & $\begin{array}{l}\text { Reactor outlet } \\
\text { temperature }\end{array}$ & Reactor power \\
\hline
\end{tabular}

Table X Description of Control System D Individual Controllers

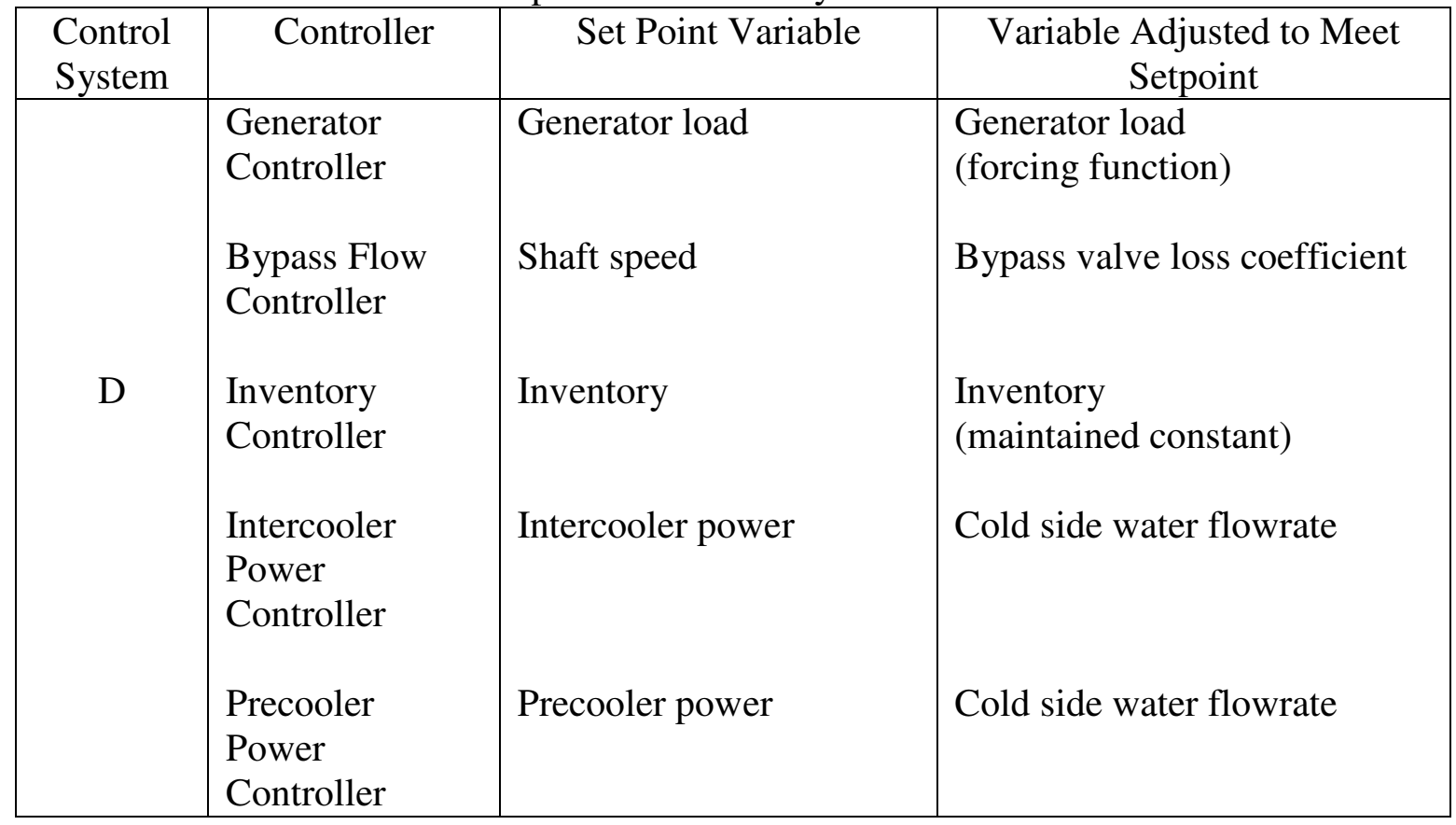




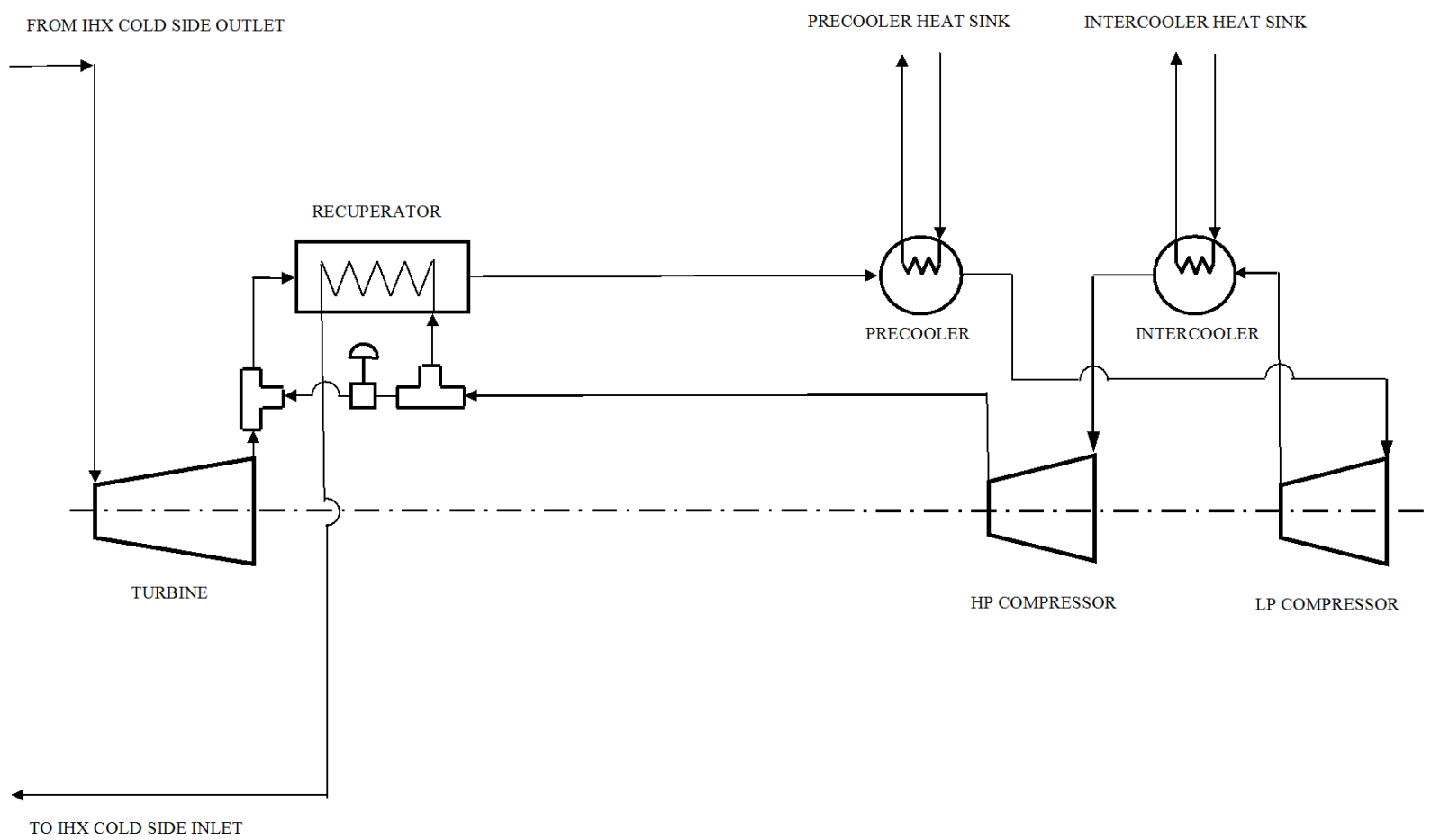

Figure 25 Reference Interface Power Conversion Unit with Bypass Valve 


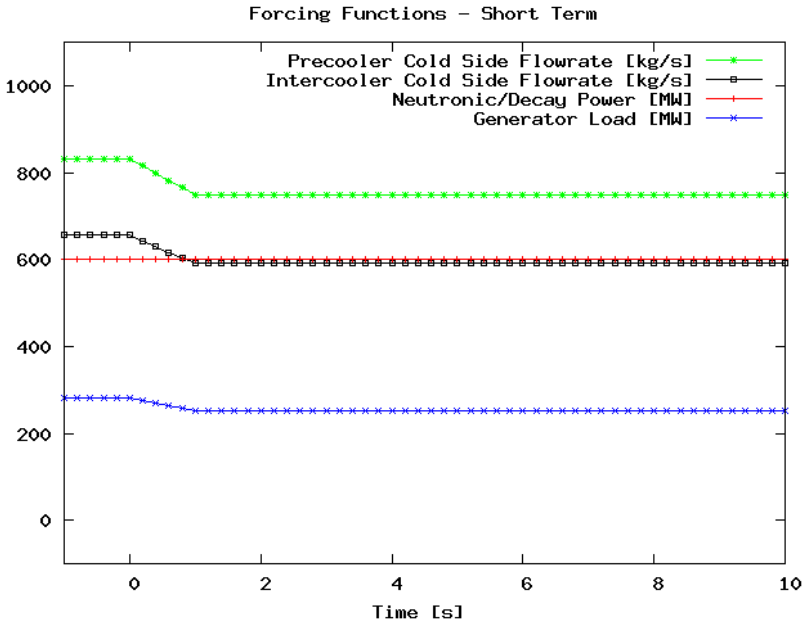

Figure 26 Step of Generator Load of Ten Percent - Forcing Functions - Short Term

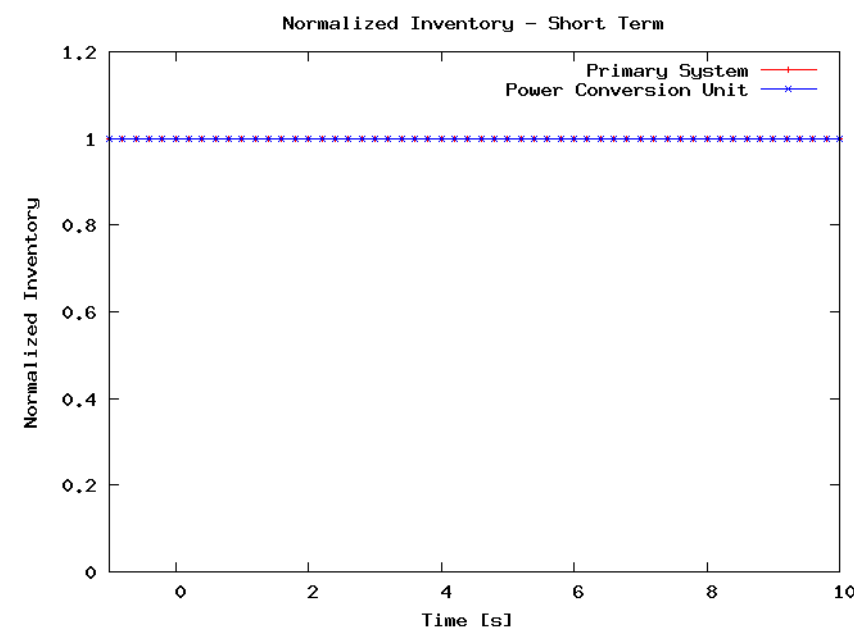

Figure 28 Step of Generator Load of Ten Percent Normalized Inventory - Short Term

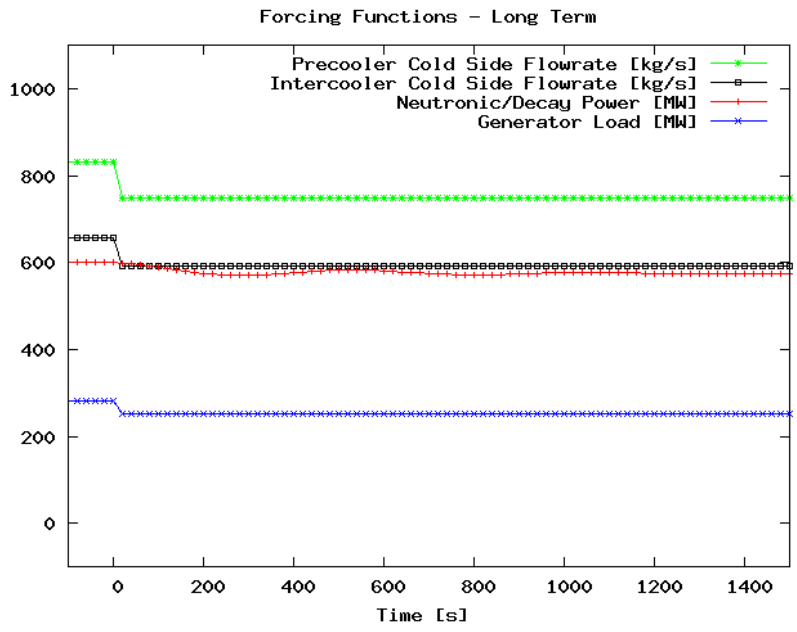

Figure 27 Step of Generator Load of Ten Percent - Forcing Functions - Long Term

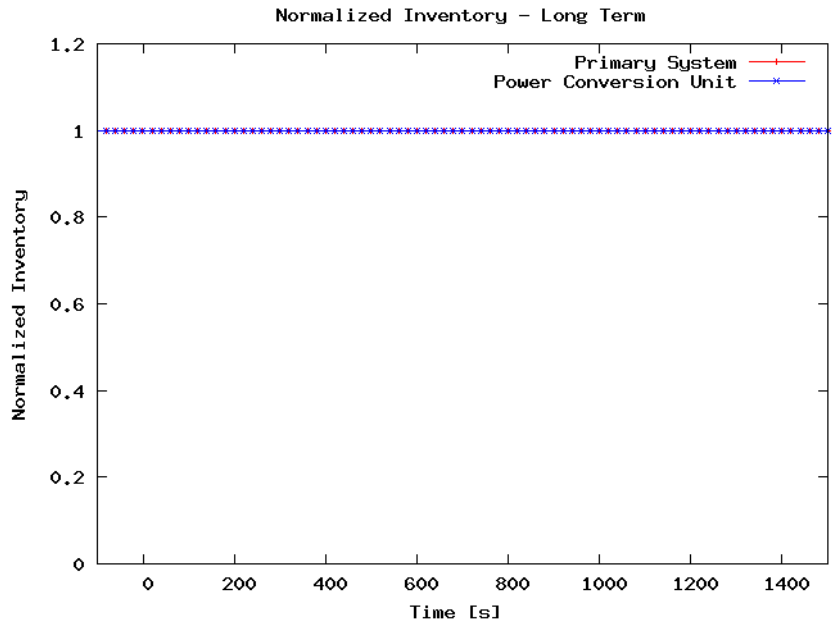

Figure 29 Step of Generator Load of Ten Percent Normalized Inventory - Long Term 


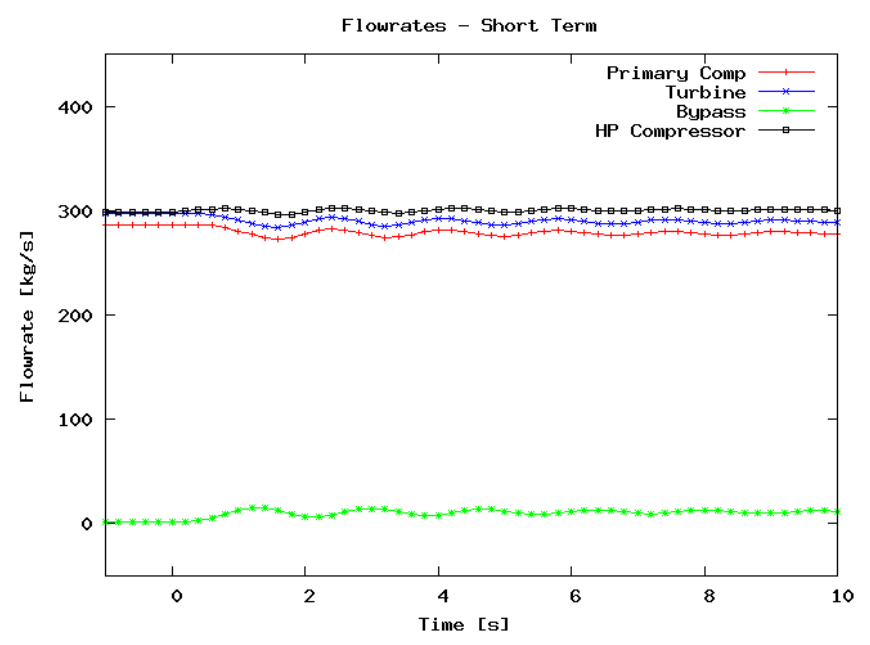

Figure 30 Step of Generator Load of Ten Percent Flowrates - Short Term

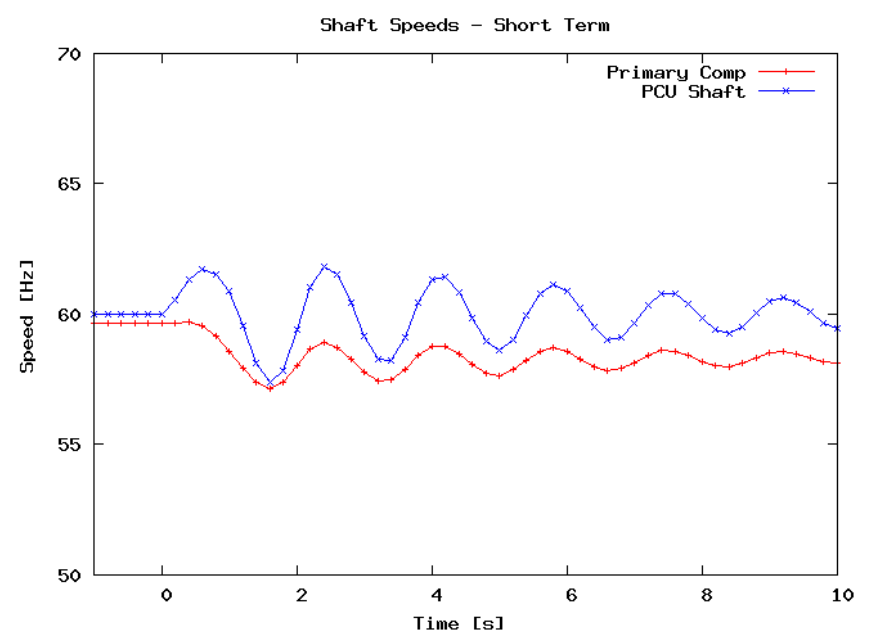

Figure 32 Step of Generator Load of Ten Percent - Shaft Speeds - Short Term

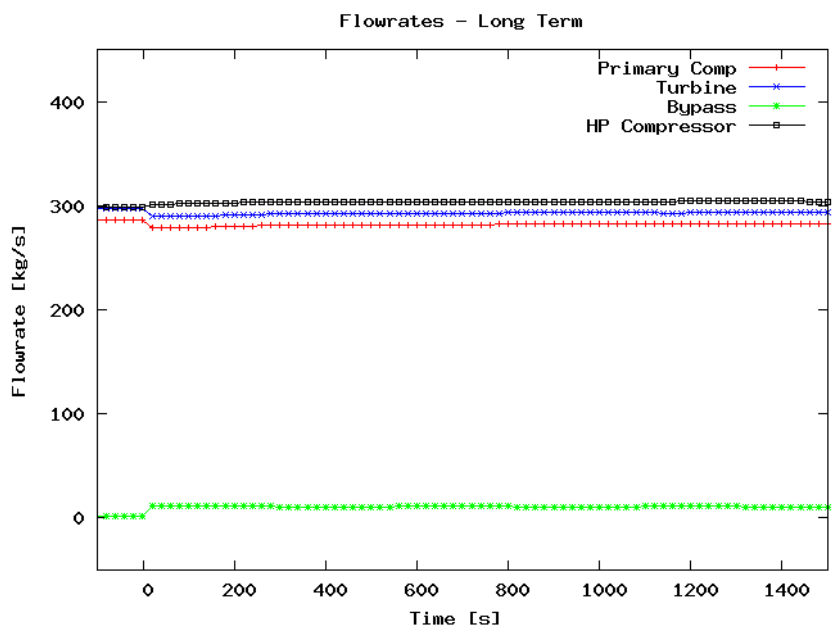

Figure 31 Step of Generator Load of Ten Percent Flowrates - Long Term

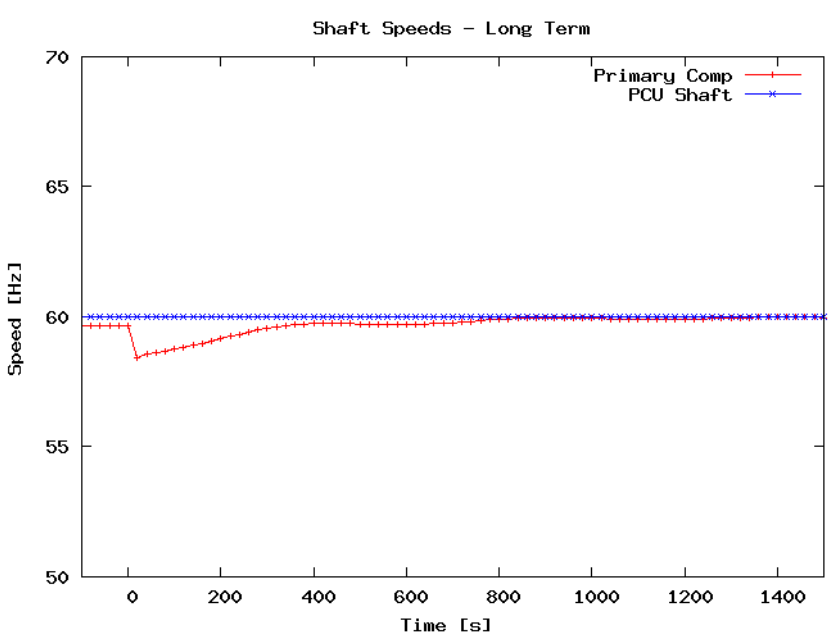

Figure 33 Step of Generator Load of Ten Percent - Shaft Speeds - Long Term 


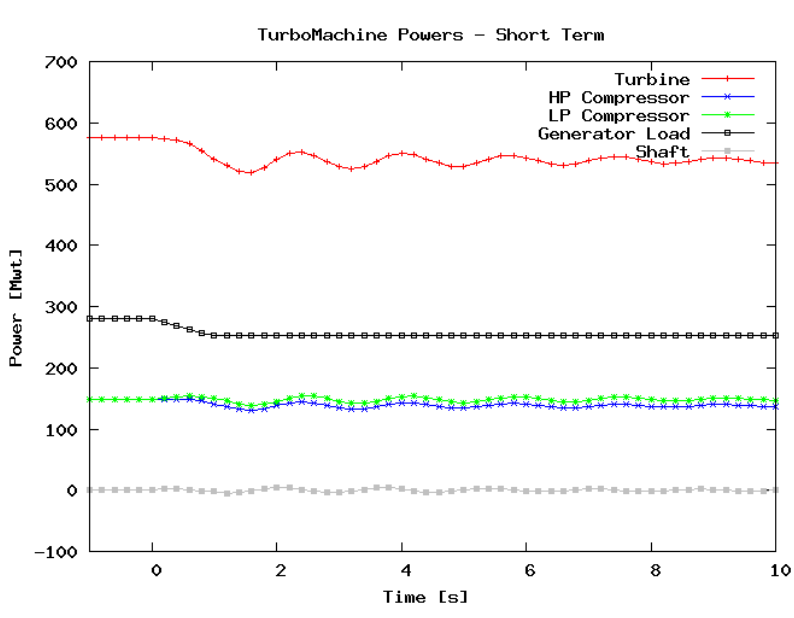

Figure 34 Step of Generator Load of Ten Percent TurboMachPowers - Short Term

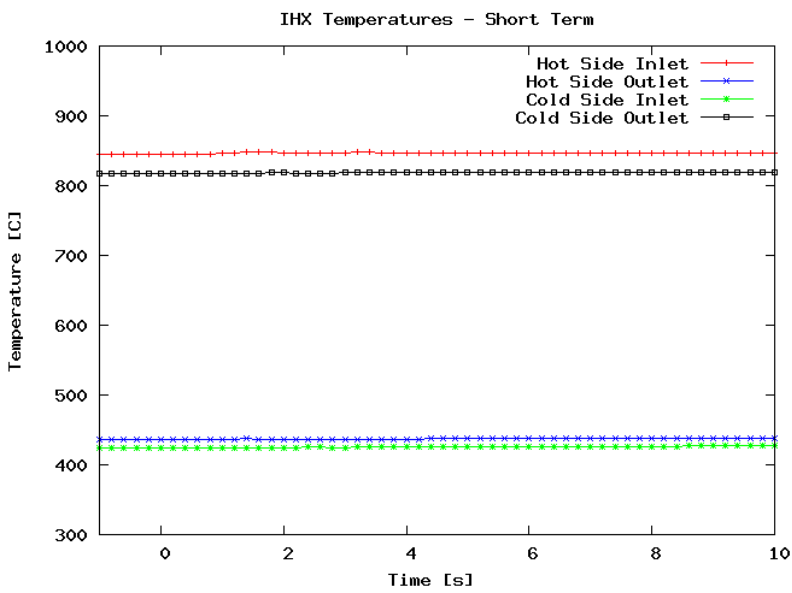

Figure 36 Step of Generator Load of Ten Percent - IHX Temperatures - Short Term

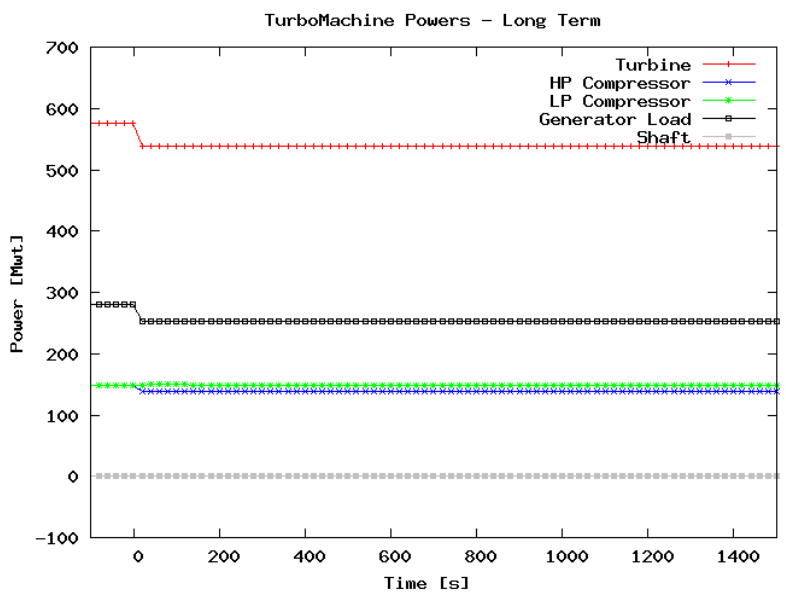

Figure 35 Step of Generator Load of Ten Percent TurboMachPowers - Long Term

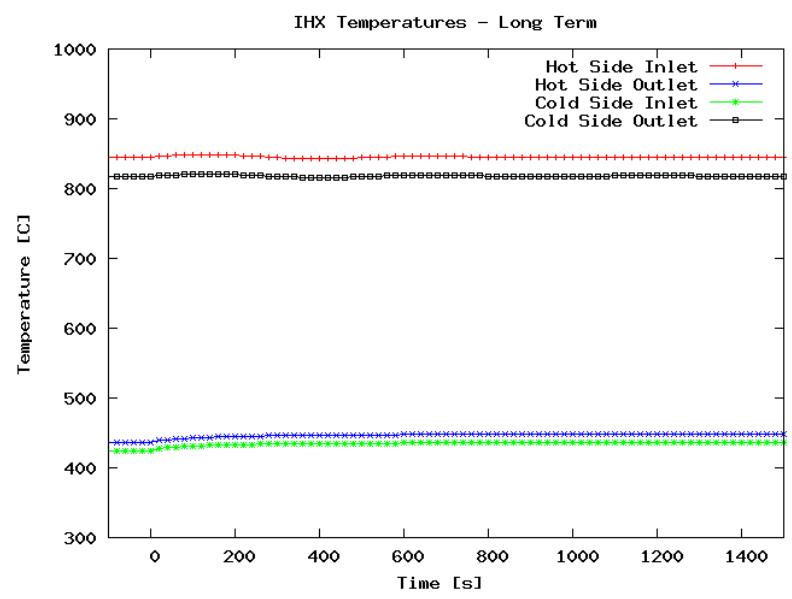

Figure 37 Step of Generator Load of Ten Percent - IHX Temperatures - Long Term 


\section{Loss of Electric Generator Load}

The HTE hydrogen plant presents largely an electric load to the nuclear plant. In the Reference Interface concept more than 93 percent of the load placed on the nuclear plant is electrical with the balance being thermal load. In an Alternate Interface concept essentially 100 percent of the HTE load is electrical. Various scenarios can be envisioned under which the generator load might quickly disconnect from the turbo-machine shaft. These include an electrical distribution fault in the hydrogen plant, an electrical fault in the generator, or the need to stop hydrogen production for safety reasons.

In the event of quick disconnect a torque imbalance occurs and the PCU shaft begins to over speed. If no control action is taken the terminal speed is a function of PCU loop friction losses and the turbomachine performance curves. To prevent damage from the over speed condition, a bypass valve is opened to redirect flow from the high pressure compressor to the outlet of the turbine. This decreases the pressure drop across the turbine and the work done by the turbine. At the same time the flow rate in the cold side of the PCU increases causing frictional losses to increase. The net effect is for over speed to be reduced as a result of decreased torque imbalance.

\section{D.1 Protected Event}

In a protected loss of electric load event the reactor scrams and power drops to decay heat levels. To avoid rapid temperature changes in the IHX the control system should function to scale back primary system flow so that it remains in proportion to decay power. In the short term the control system must also function to prevent large temperature rates of change in the IHX following bypass valve opening. In the longer term the challenge is on one hand to remove enough power to keep the PCU functioning as a heat engine so that the reactor is cooled and on the other hand not remove energy at a high enough rate that the reactor is overcooled. Notwithstanding, at some point the decay heat will fall to a level where heat engine operation cannot be sustained without drawing on reactor stored energy. This would be the appropriate time to trip the primary pump, trip the coolers, and go into Shutdown Cooling System (SCS) mode of operation.

To avoid shaft over speed on loss of load, the bypass valve is opened to raise the outlet pressure of the turbine so that it is closer to the inlet pressure thereby reducing the shaft work performed by the turbine. A bypass line containing the bypass valve serves to divert high pressure compressor outlet coolant around the reactor and turbine. The bypass line connects the compressor outlet to the recuperator hot side inlet as shown in Figure 25.

A control strategy for managing temperatures was investigated for the protected loss of load event. A simulation was performed using the forcing functions shown in Figure 38 and 39. Two dollars of negative reactivity were inserted into the core linearly over a one second interval. The resulting neutronic/decay power is shown in Figure 38. The generator load on the PCU shaft was linearly reduced to zero over the same one second interval. The cooler powers were controlled by varying the cold side water flow rates. 
The control systems enabled in the simulation were: 1) the IHX Flow Balance Controller which acts through primary compressor speed to maintain equal flow rate on the hot and cold sides of the IHX and 2) the Bypass Flow Controller which acts through bypass valve loss coefficient to maintain a shaft speed setpoint. Additionally the precooler and intercooler cold side flow rates are supplied as forcing functions. The flowrates were roughly matched to decay heat level. The PCU shaft setpoint is decreased from $60 \mathrm{~Hz}$ over time to have the shaft speed more or less track the decreasing reactor energy production rate.

The plant response appears in Figures 40 through 49. The PCU shaft speed response appears in Figure 44 and 45 . There is an initial overshoot in the first second as the controller attempts to maintain $60 \mathrm{~Hz}$. The overshoot dies out within three seconds and the speed returns to the setpoint value. The permissible magnitude and time rate of change of the overshoot is governed by mechanical design considerations. The constants in the PI speed controller can be modified as needed to reduce overshoot. Bypass flow rate shown in Figure 42 peaks at almost half of the full power PCU flowrate.

The IHX temperature response appears is Figure 48 and 49. The IHX Flow Balance controller is effective in maintaining equal hot and cold side flow rates as appears in Figure 43. As a result the temperature changes from hot to cold side of the IHX remain near constant. Beyond $100 \mathrm{~s}$ the primary system may actually be overcooled. The IHX temperatures are dropping at a rate of about half a degree Celsius per second. This rate of change is large and probably not desirable. The possibility of changing PCU operating modes at about $100 \mathrm{~s}$ so it is no longer working as a heat engine should be explored. Instead the coolers should probably be turned off, the shaft allowed to coast down, and the primary flowrate continue to be managed to maintain constant temperatures between the hot and cold side of the IHX. 


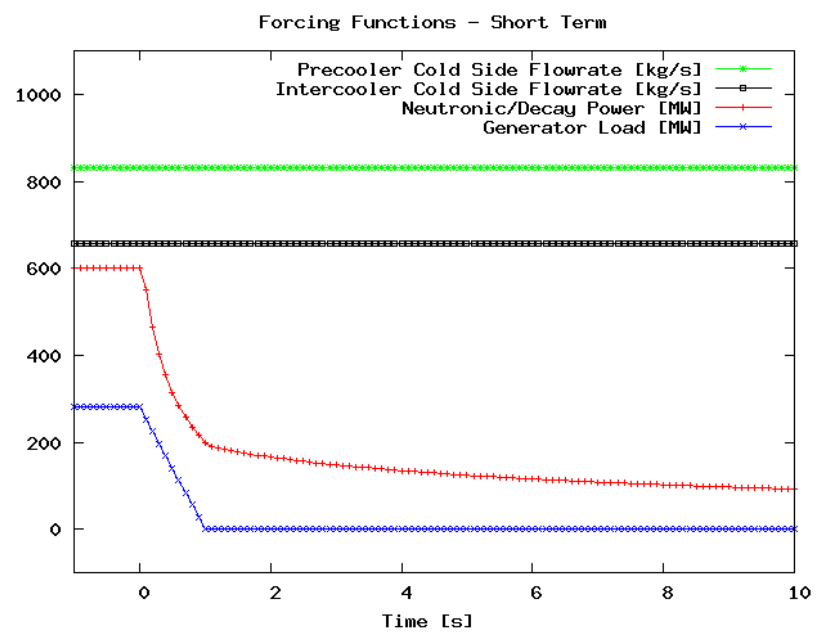

Figure 38 Protected Loss of Generator Load - Forcing Functions - Short Term

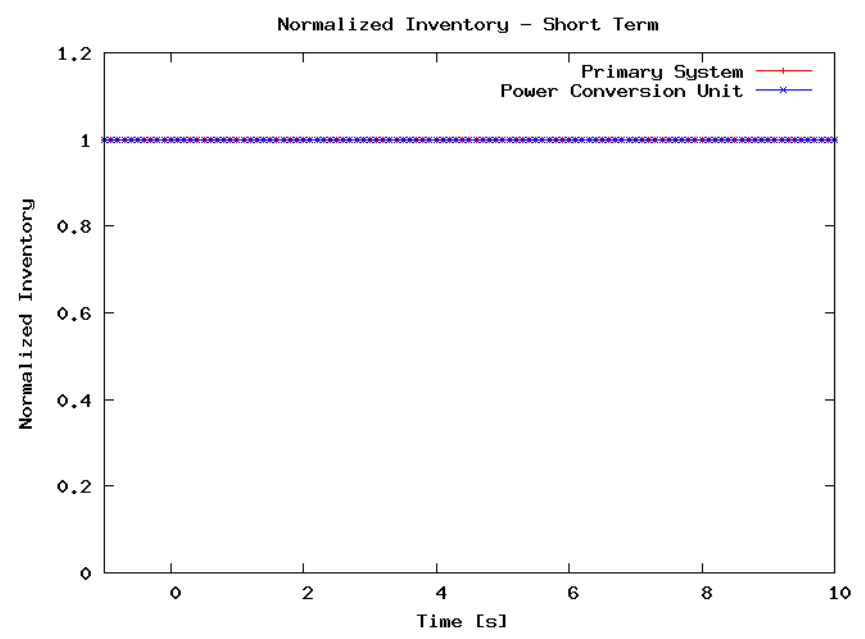

Figure 40 Protected Loss of Generator Load - Normalized Inventory - Short Term

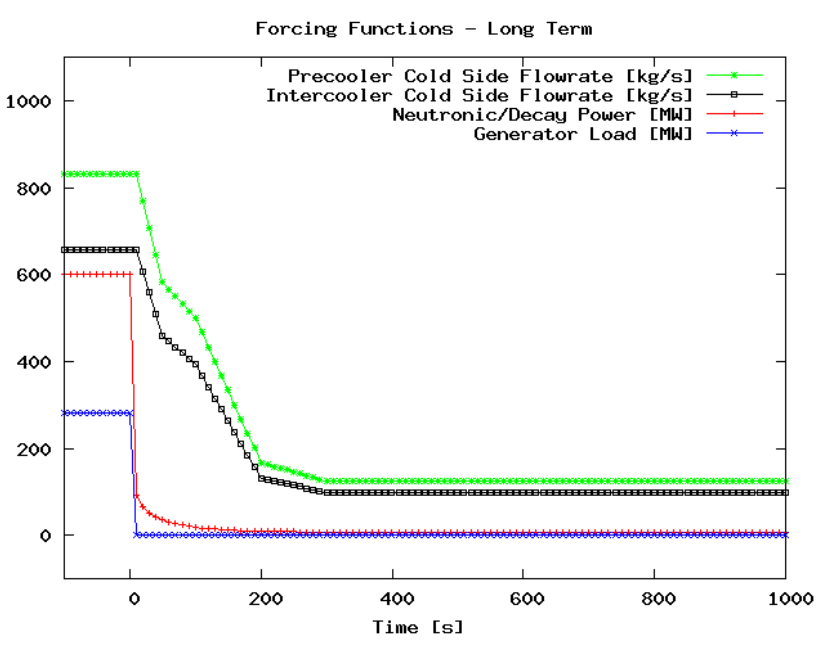

Figure 39 Protected Loss of Generator Load - Forcing Functions - Long Term

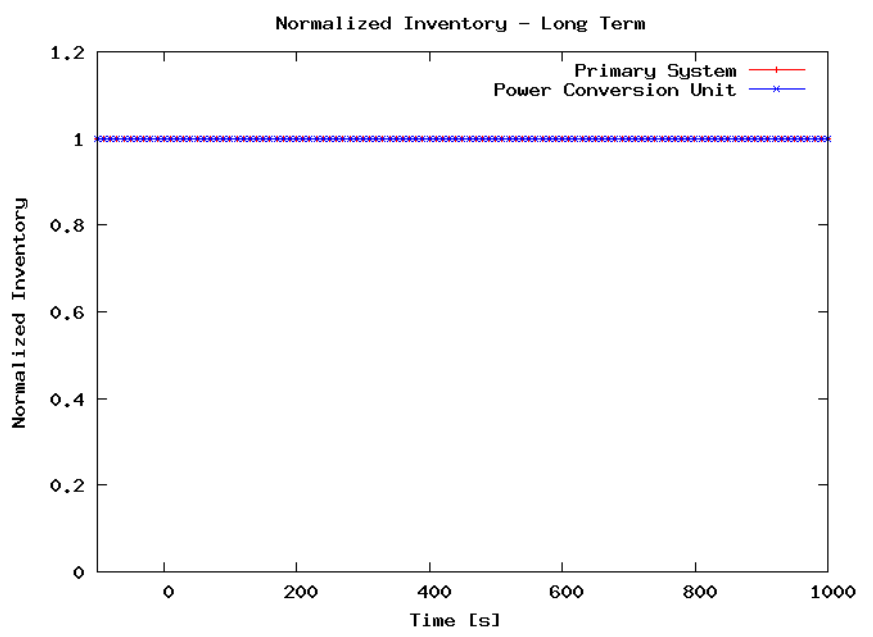

Figure 41 Protected Loss of Generator Load - Normalized Inventory - Long Term 


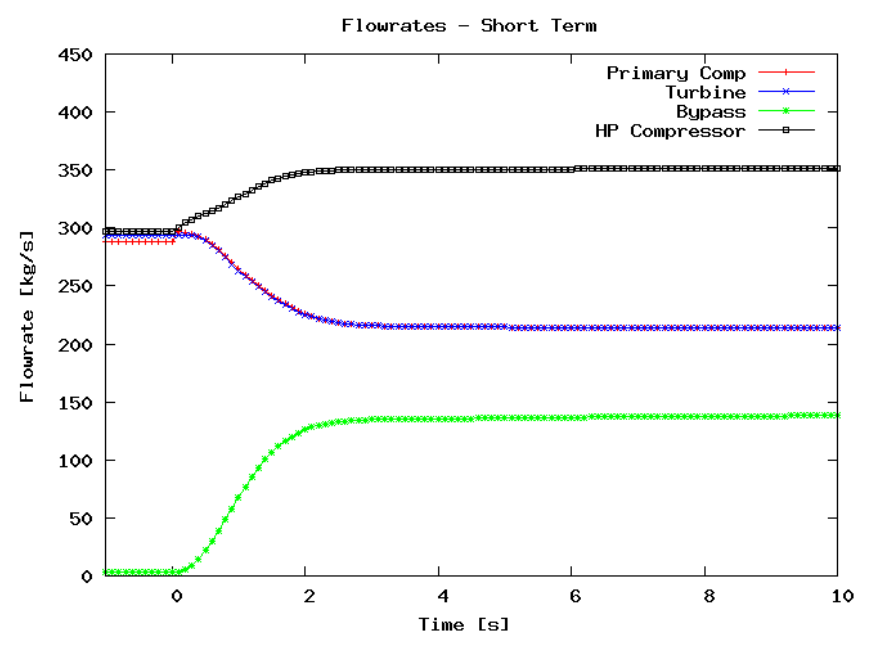

Figure 42 Protected Loss of Generator Load - Mass Flowrates - Short Term

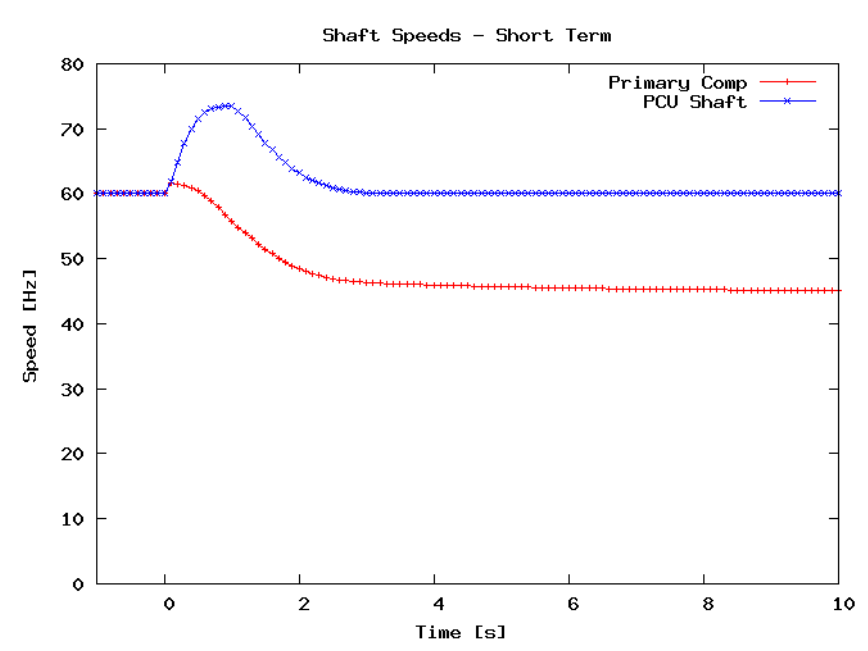

Figure 44 Protected Loss of Generator Load - Shaft Speeds - Short Term

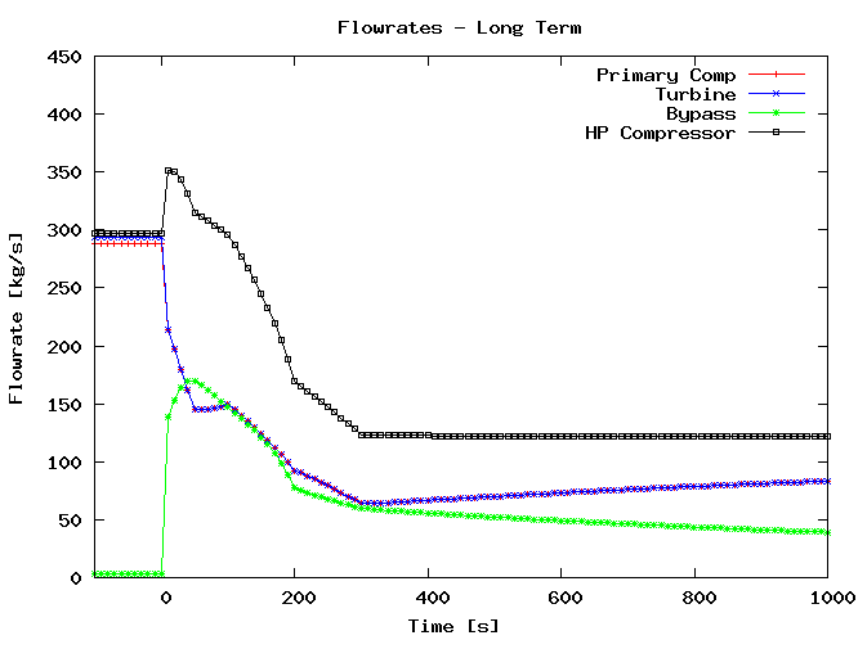

Figure 43 Protected Loss of Generator Load - Mass Flowrates - Long Term

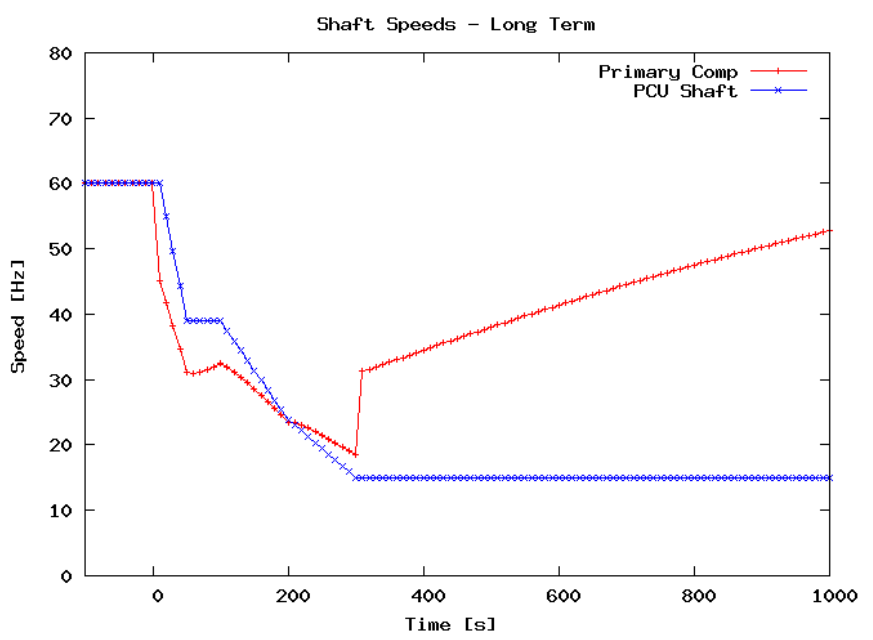

Figure 45 Protected Loss of Generator Load - Shaft Speeds - Long Term 


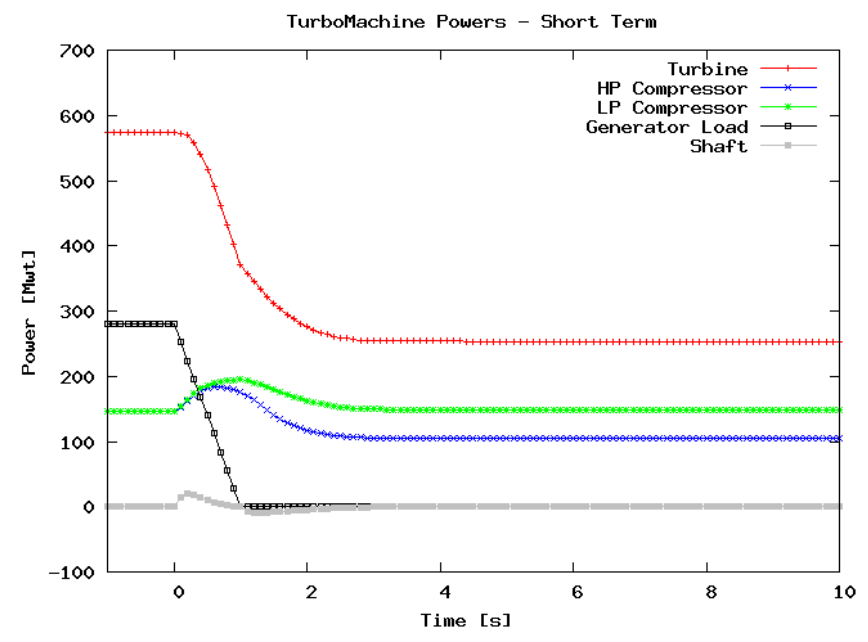

Figure 46 Protected Loss of Generator Load TurboMachine Powers - Short Term

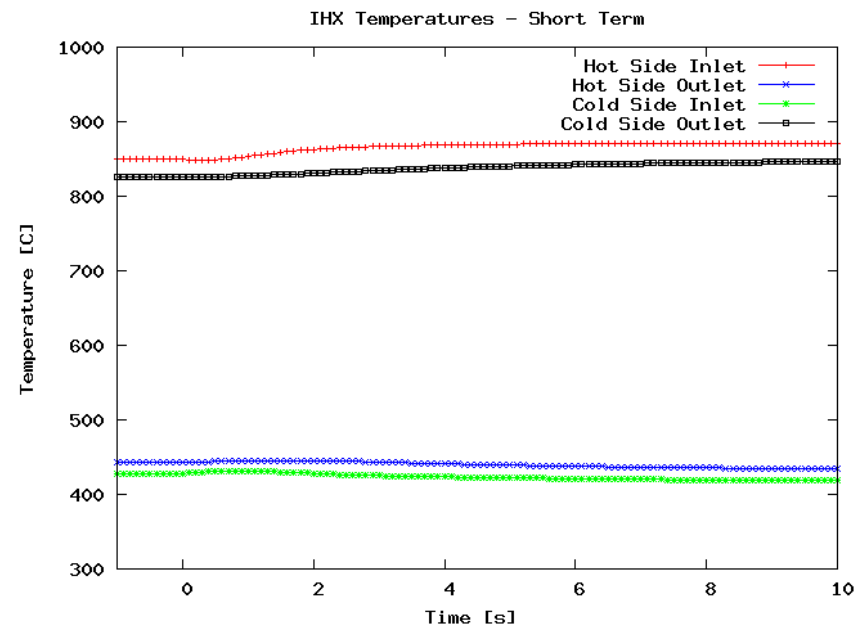

Figure 48 Protected Loss of Generator Load - IHX Temperatures - Short Term

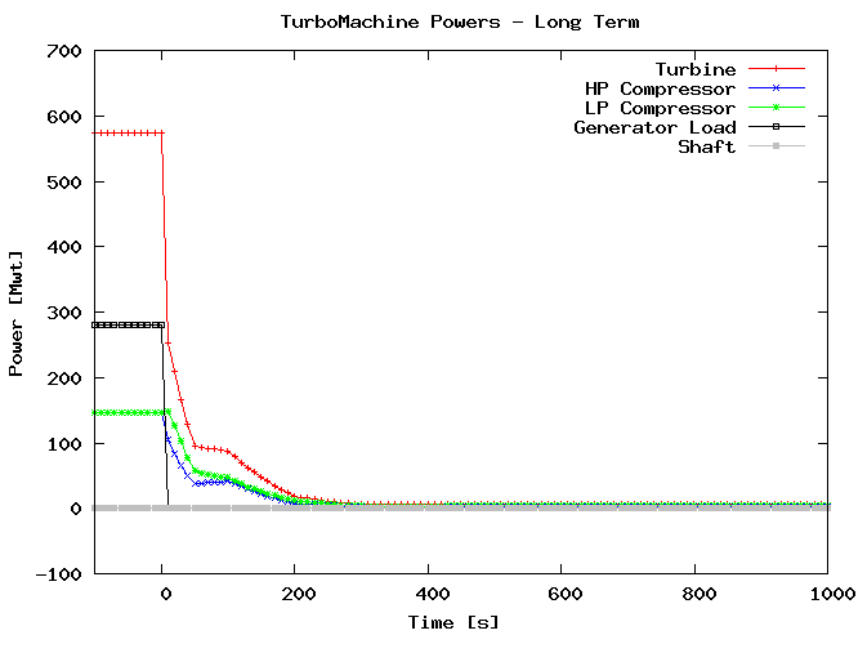

Figure 47 Protected Loss of Generator Load TurboMachine Powers - Long Term

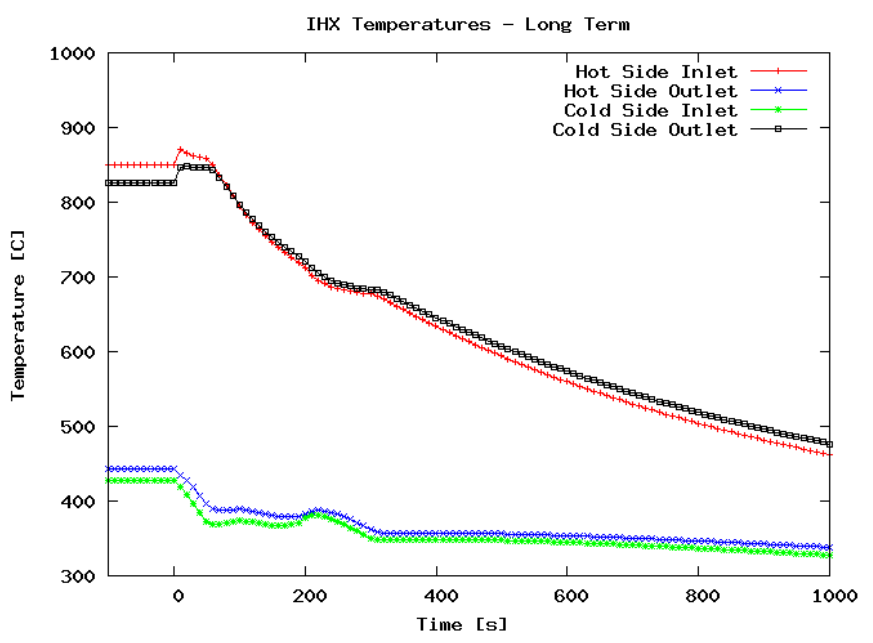

Figure 49 Protected Loss of Generator Load - IHX Temperatures - Long Term 


\section{D.2 Unprotected Event}

The NGNP safety analysis must address a class of upsets referred to as Anticipated Transients without Scram (ATWS). For this class of upsets it must be shown that the plant control system is capable of maintaining a safe operating state following an assumed failure of the protection system to scram the reactor. The initiating upsets are expected to normally occur during the life of the plant.

The loss of electric load is one of these initiating ATWS upsets. Some of the same issues that exist in the protected case also exist for the unprotected case. But in addition, since the reactor is still critical, there is the possibility for self-regulation of heat production with consequent mitigation of rates of temperature change. This is explored below in a transient simulation.

The upset begins with a loss of generator electric load as shown in Figure 50. The control system is assumed to reduce the precooler and intercooler powers by reducing cold side flowrate as shown in Figure 50. The objective is to bring the long term heat removal rate into balance with the reactor power which should be decreased to move the plant toward a shutdown state. Failure to reduce the power of the coolers will overcool the plant and cause the reactor inlet temperature to drop. This will add reactivity through a negative inlet temperature coefficient and work against bringing the core power down. The inherent neutronic/decay heat power response resulting from fuel and graphite reactivity temperature feedback is shown in Figures 50 and 51.

The NGNP response begins with the shaft over speeding as shown in Figure 56 on torque imbalance with the loss of the generator electrical load. The average reactor temperature inferred from the IHX hot side temperatures in Figure 61 rises as the cooler heat rates are reduced. At about $400 \mathrm{~s}$ the reactor power (seen in Figure 51) driven by reactivity temperature feedbacks comes into equilibrium with the cooler heat rates. The reactor has reached a new equilibrium critical state. The hot side temperature in the reactor and in the IHX remain essentially constant for the duration of the transient as seen in Figure 61. (Note: The neutronic/decay power was included in Figure 50 and 51 for ease of comparison with other important variables. Contrary to the figure caption neutronic/decay power was not a forcing function.) 


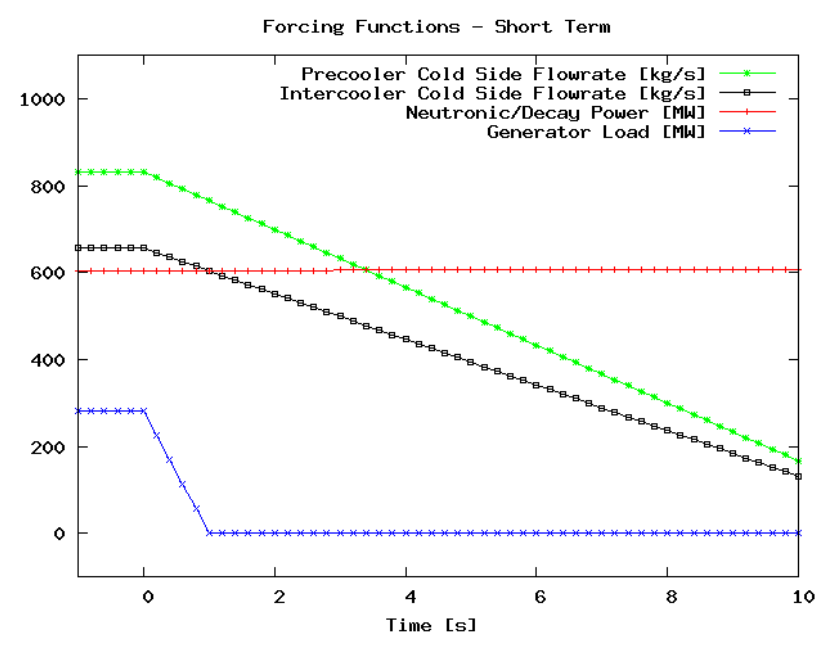

Figure 50 Unprotected Loss of Generator Load - Forcing Functions - Short Term

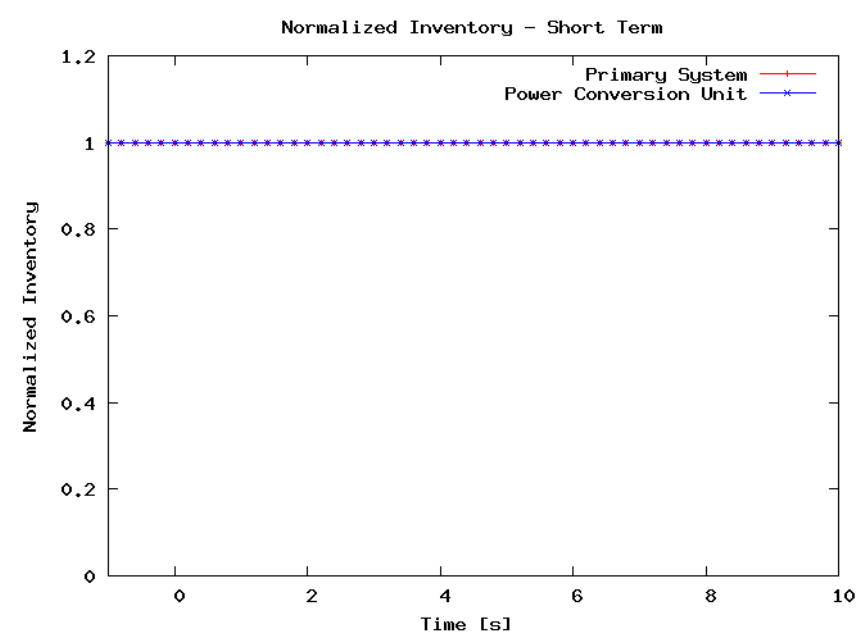

Figure 52 Unprotected Loss of Generator Load Normalized Inventory - Short Term

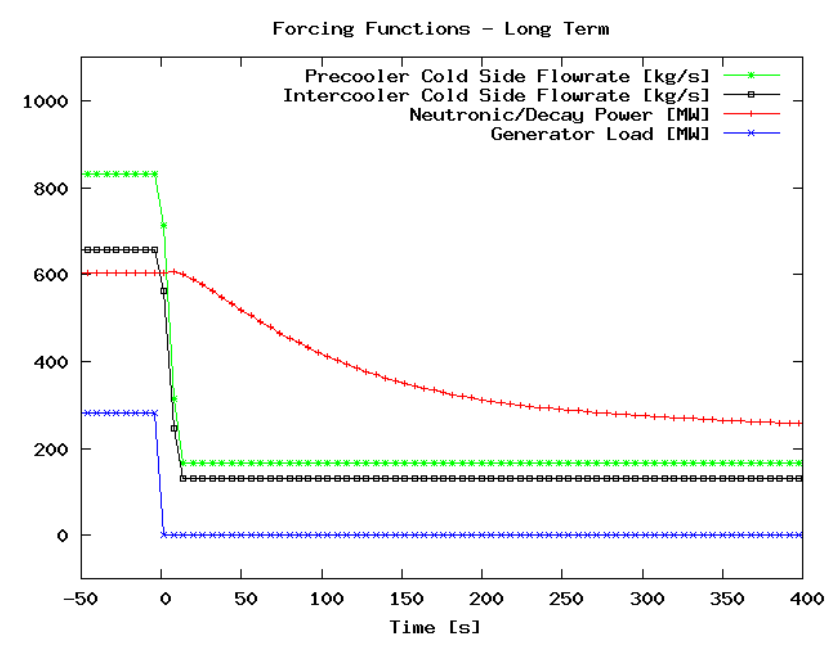

Figure 51 Unprotected Loss of Generator Load - Forcing Functions - Long Term

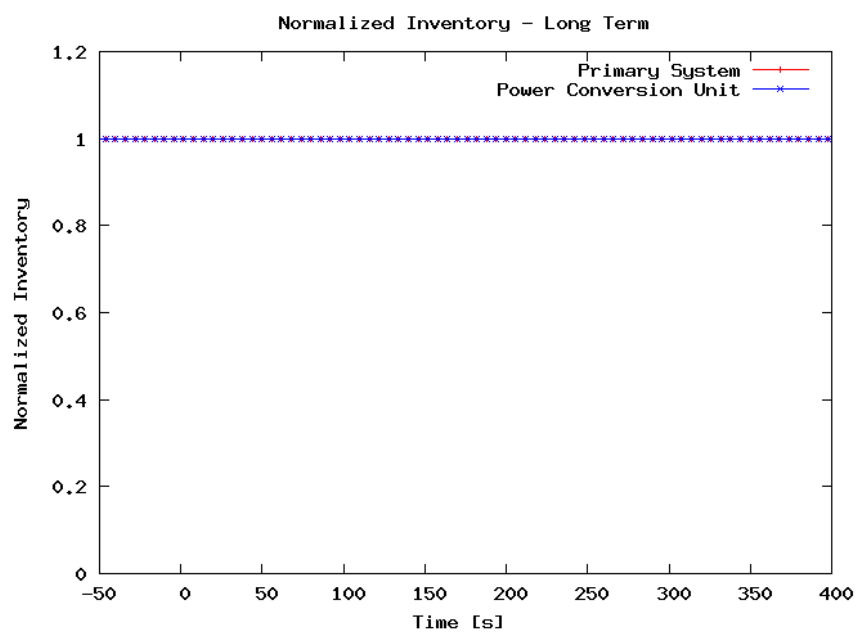

Figure 53 Unprotected Loss of Generator Load Normalized Inventory - Long Term 


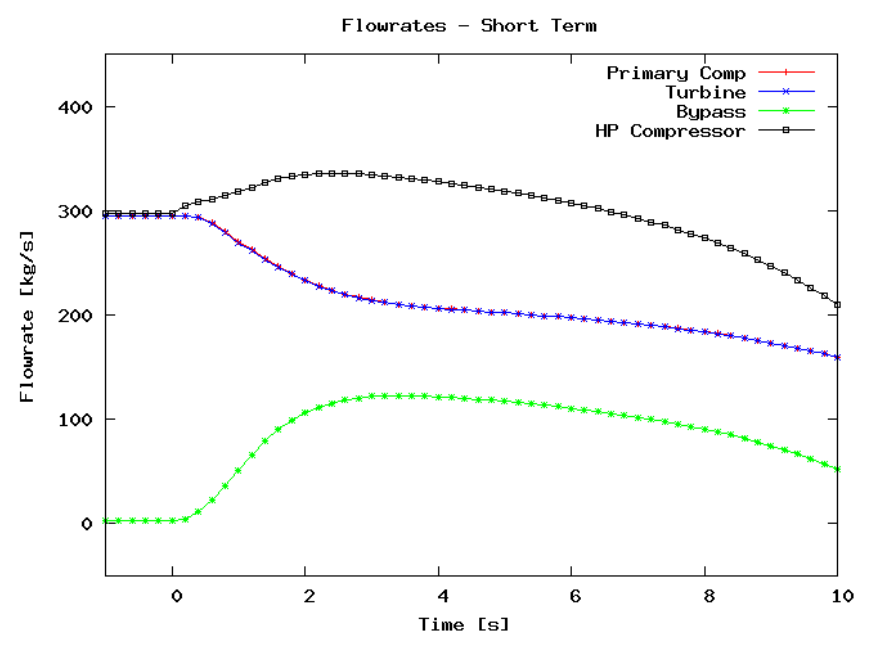

Figure 54 Unprotected Loss of Generator Load - Mass Flowrates - Short Term

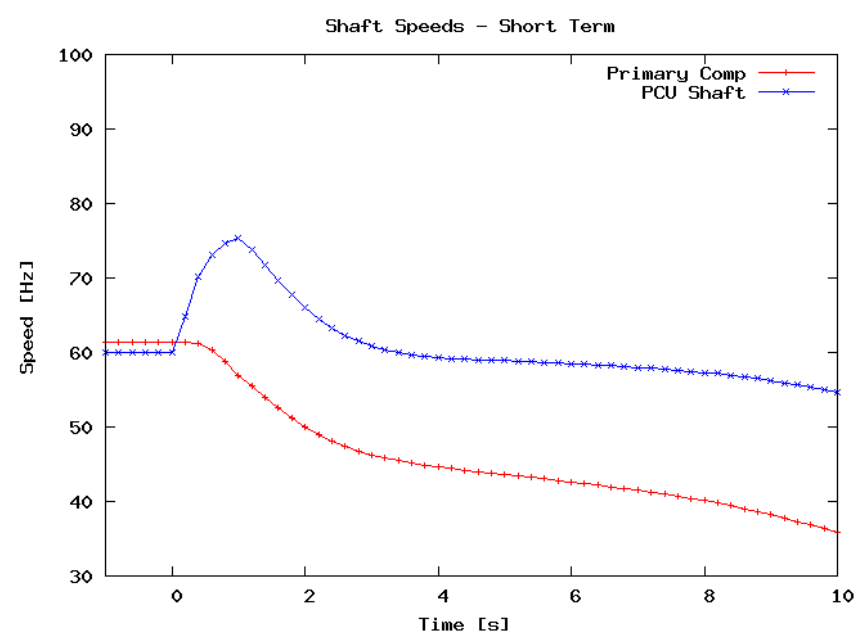

Figure 56 Unprotected Loss of Generator Load - Shaft Speeds - Short Term

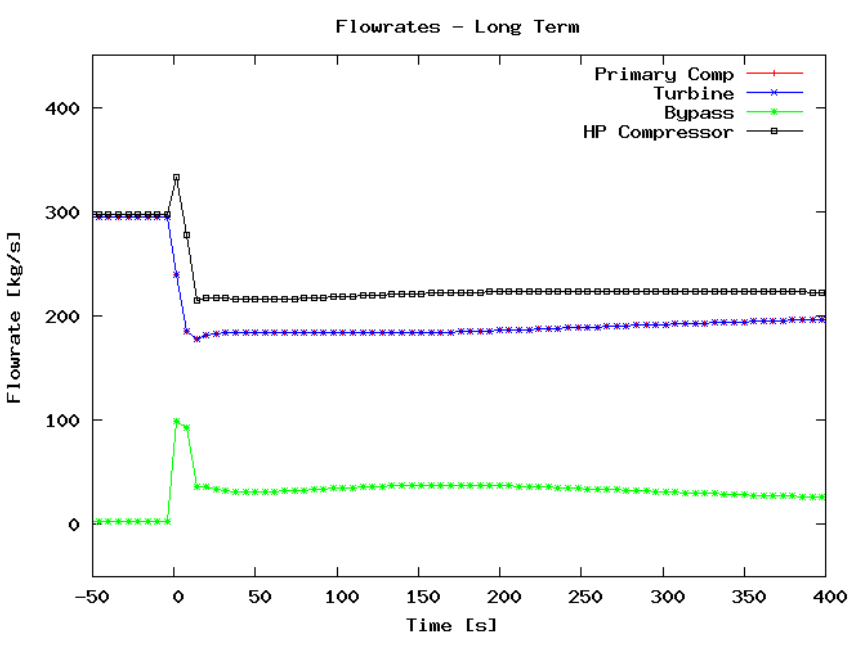

Figure 55 Unprotected Loss of Generator Load - Mass Flowrates - Long Term

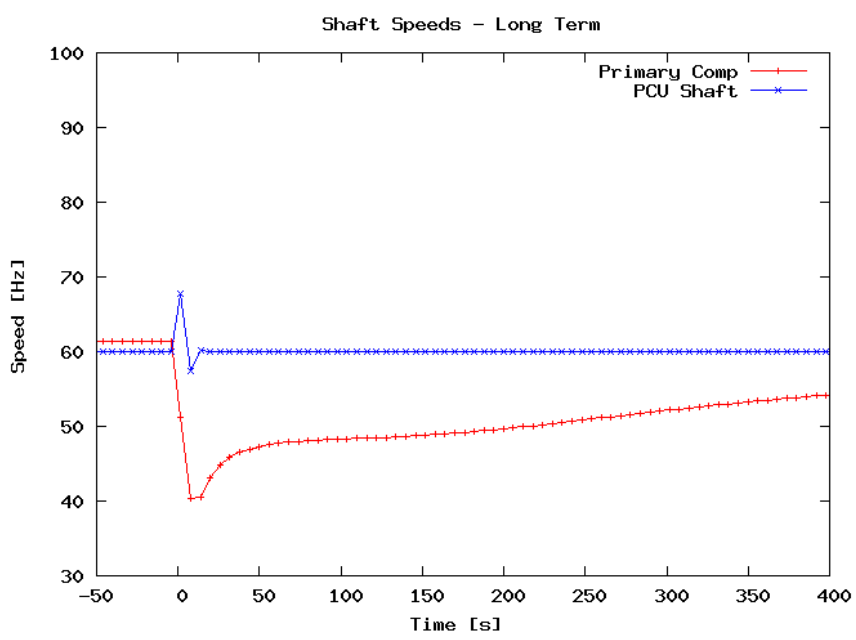

Figure 57 Unprotected Loss of Generator Load - Shaft Speeds - Long Term 


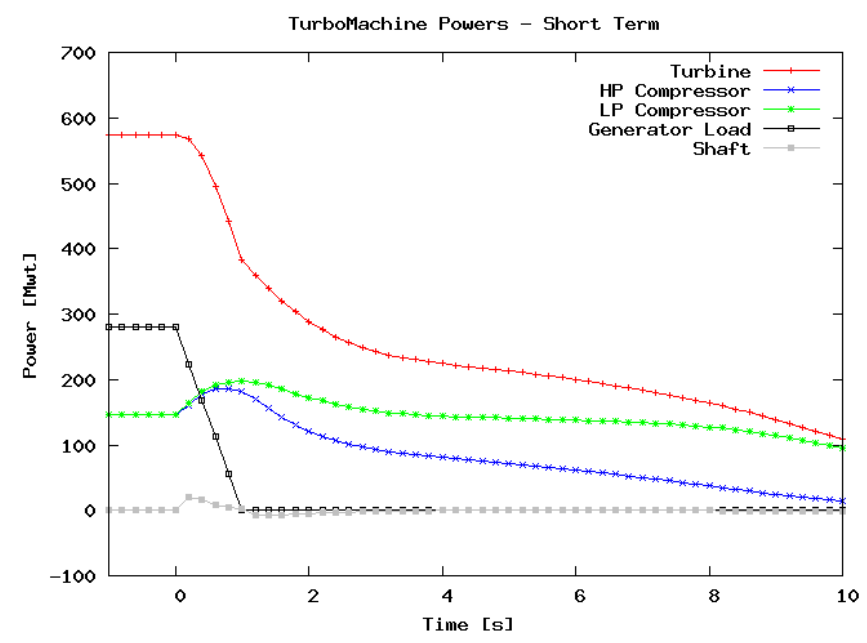

Figure 58 Unprotected Loss of Generator Load TurboMachPowers - Short Term

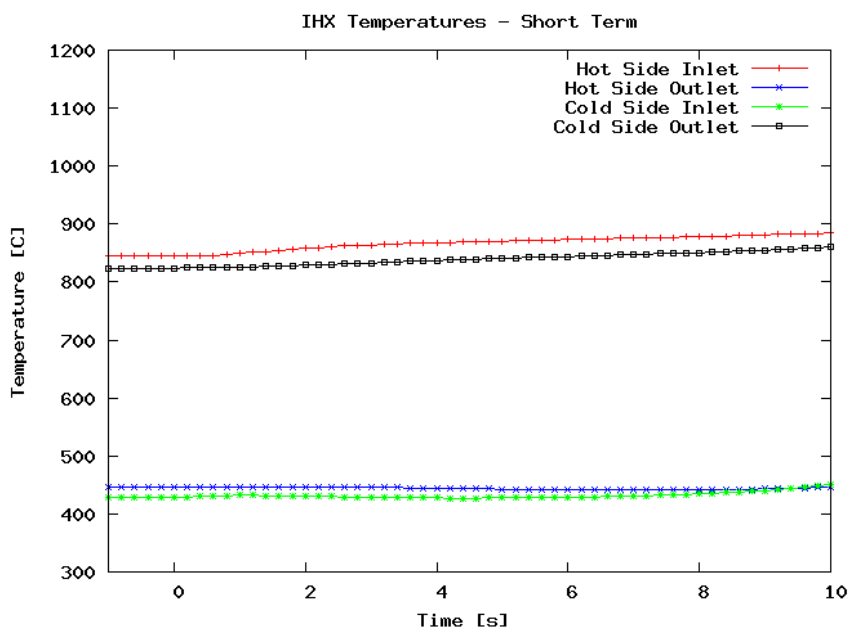

Figure 60 Unprotected Loss of Generator Load - IHX Temperatures - Short Term

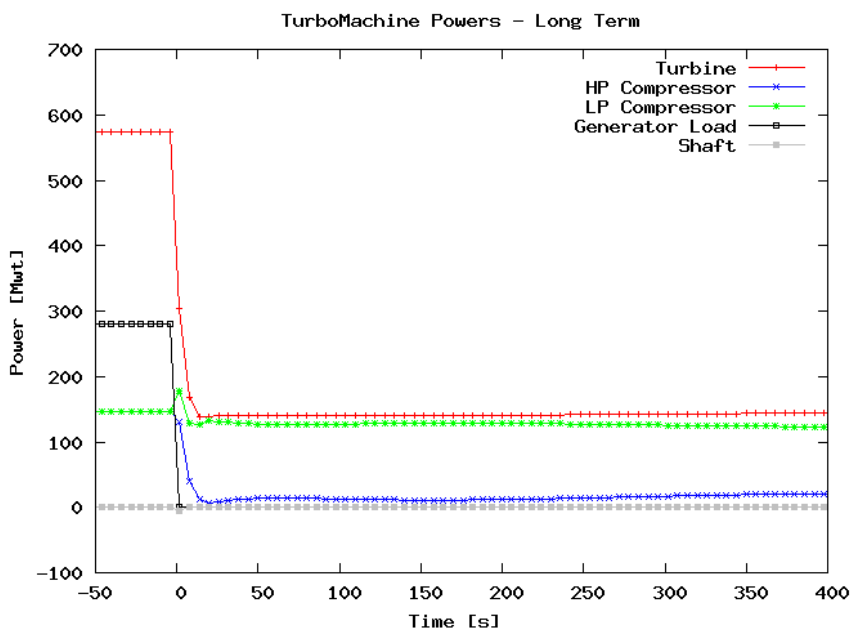

Figure 59 Unprotected Loss of Generator Load TurboMachPowers - Long Term

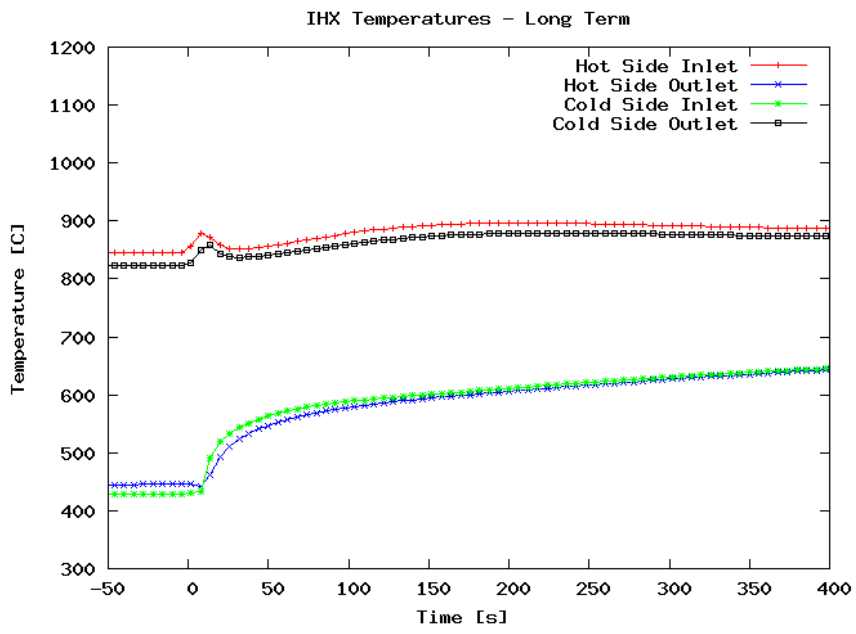

Figure 61 Unprotected Loss of Generator Load - IHX Temperatures - Long Term 


\section{CONCLUSIONS}

Control system studies were performed for the Next Generation Nuclear Plant (NGNP) interfaced to the High Temperature Electrolysis (HTE) plant. Temperature change and associated thermal stresses are important factors in determining plant lifetime. In the NGNP the design objective of a 40 year lifetime for the Intermediate Heat Exchanger (IHX) in particular is seen as a challenge. A control system was designed to minimize temperature changes in the IHX and more generally at all high-temperature locations in the plant for duty-cycle transients. In the NGNP this includes structures at the reactor outlet and at the inlet to the turbine.

This problem was approached by identifying those high-level factors that determine temperature rates of change. First are the set of duty cycle transients over which the control engineer has little control but which none-the-less must be addressed. Second is the partitioning of the temperature response into a quasi-static component and a transient component. These two components are largely independent of each other and when addressed as such greater understanding of temperature change mechanisms and how to deal with them is achieved. Third is the manner in which energy and mass flow rates are managed. Generally one aims for a temperature distribution that minimizes spatial non-uniformity of thermal expansion in a component with time. This is can be achieved by maintaining a fixed spatial temperature distribution in a component during transients. A general rule of thumb for heat exchangers is to maintain flow rate proportional to thermal power. Additionally the product of instantaneous flow rate and heat capacity should be maintained the same on both sides of the heat exchanger. Fourth inherent mechanisms for stable behavior should not be compromised by active controllers that can introduce new feedback paths and potentially create under-damped response.

Applications of these principles to the development of a plant control strategy for the reference NGNP/HTE plant can be found in the body of this report. The outcome is an integrated plant/control system design. The following conclusions are drawn from the analysis.

$\circ$ The plant load schedule can be managed to maintain near-constant hot side temperatures over the load range in both the nuclear and chemical plant.

- The reactor open-loop response is inherently stable resulting mainly from a large Doppler temperature coefficient compared to the other reactivity temperature feedbacks.

- The typical controller used to manage reactor power production to maintain reactor outlet temperature at a setpoint introduces a feedback path that tends to destabilize reactor power production in the NGNP.

- A primary loop flow controller that forces primary flow to track PCU flow rate is effective in minimizing spatial temperature differentials within the IHX.

- Inventory control in both the primary and PCU system during ramp load change transients is an effective means of maintaining high NGNP thermal efficiency while at reduced electric load. 
- Turbine bypass control is an effective means for responding to step changes in generator load when equipment capacity limitations prevent inventory control from being effective.

- Turbine bypass control is effective in limiting PCU shaft over speed for the loss of generator load upset event.

- The proposed control strategy is effective in limiting time variation of the differential spatial temperature distribution in the IHX during transients. Essentially the IHX can be made to behave in a manner where each point in the IHX experiences approximately the same temperature rate of change during a transient.

- The stability of the closed-loop Brayton cycle was found to be sensitive to where one operates on the turbo-machine performance maps. There are competing interests: more stable operation means operating on the curves at points that reduce overall cycle efficiency.

Future work should address in greater detail elements that came to light in the course of this work. Specifically:

- A stability analysis should be performed to identify the phenomena that control reactor outlet temperature stability when operating with the Reactor Outlet Temperature Controller. The goal is to identify a better performing controller.

- Future simulations should be performed with multiple axial nodes. The single axial node model for the core used in this work gives rise to an initial core reactor outlet temperature perturbation that is a numerical artifact.

- The tradeoffs referred to above regarding the dependence of Brayton cycle stability and efficiency on performance curve characteristics and use need to be better understood.

- The role of xenon was neglected in this work and needs to be included in future work. 


\section{REFERENCES}

1. R.B. Vilim, "Alternate VHTR/HTE Interface for Mitigating Tritium Transport and Structure Creep,” ANL-GenIV-102, March 2008

2. R.B. Vilim, "NGNP/HTE Full-Power Operation at Reduced High-Temperature Heat Exchanger Temperatures," ANL-GenIV-105, July 2008.

3. Oh C. H., et al., "HyPEP FY06 Report: Models and Methods," INL/EXT-06-11725, 2006.

4. $\quad$ Davis C.B., Oh C.H., Barner R.B., Sherman S.R., and Wilson D.F., ThermalHydraulic Analyses of Heat Transfer Fluid Requirements and Characteristics for Coupling a Hydrogen Production Plant to a High-Temperature Nuclear Reactor, INL/EXT-05-00453, June 2006.

5. R.B. Vilim, "Initial Assessment of the Operability of the VHTR-HTE Nuclear Hydrogen Plant," ANL-08/01, September 2007

6. McKellar, M. G., O’Brien, J. E., Harvego E. A., and Herring J. S., "Optimized FlowSheet for a Reference Commercial-Scale Nuclear-Driven High Temperature Electrolysis Hydrogen Production Plant”, DOE Milestone Report, November 14, 2007.

7. C.M. Stoots, "Engineering Process Model for High-Temperature Electrolysis System Performance Evaluation,” Idaho National Laboratory, June 2005

8. R.B. Vilim, "Power Requirements at the VHTR/HTE Interface for Hydrogen Production," Proceedings of ICAPP 2007 Nice, France, May 13-18, 2007.

9. R. B. Vilim, J. Cahalan, and U. Mertyurek, "G-PASS: A Simulation Code for Gas Reactor Plant Systems,” ICAPP 2004, Pittsburgh, PA, June 2004.

10. N. Carstens, "Control Strategies for Supercritical Carbon Dioxide Power Conversion Systems," MIT Department of Nuclear Science and Engineering Ph.D. thesis, June 2007.

11. R.B. Vilim, "Initial Assessment of the Operability of the VHTR-HTSE Nuclear Hydrogen Plant," ANL-08/01, September 2007.

12. F. E. Dunn, F. G. Prohammer, G. Birgersson, L. L. Briggs, J. E. Cahalan, R. B. Vilim and D. P. Weber, "The SASSYS-1 LMFBR Systems Analysis Code," ANL/RAS 84-14, Argonne National Laboratory (February 1988).

13. C.H. Oh, E.S. Kim, S.R. Sherman, and R. Vilim, "HyPEP FY-07 Report: System Model Integration Model Development,” INL/EXT-07-12470, April 2007. 
14. Gas Turbine-Modular Helium Reactor (GT-MHR) Conceptual Design Report, Report number 910720/1, General Atomics, July 1996.

15. R. B. Vilim, "Dynamic Modeling Efforts for System Interface Interface Studies," Nuclear Hydrogen Initiative Topical Report, ANL-07/16, Argonne National Laboratory, December 2006.

16. P. MacDonald, "NGNP Point Design - Results of the Initial Neutronics and ThermalHydraulics Assessments during FY-03," INEEL/EXT-03-00870 Ref. 1, September 2003. 
Argonne

Nuclear Engineering Division

Argonne National Laboratory

9700 South Cass Avenue, Bldg. 208

Argonne, IL 60439-4842

www.anl.gov

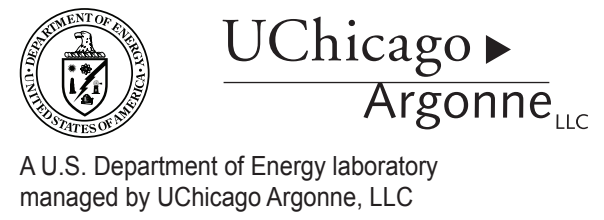

